UMR 5824

93. chemin des Mouilles 69130 Ecully - France

Maison de l'Universite, Bâtiment B 10, rue Trefilerie 42023 Saint-Etienne cedex $02 \cdot$ France

http://www.gate.cnrs.fr gate@gate.cnrs.fr

\title{
Effects of cluster policies on regional innovation networks: Evidence from France
}

\author{
Konan Alain N'Ghauran, Corinne Autant-Bernard
}

\begin{abstract}
:
Despite the growing body of literature evaluating cluster policies, it still remains difficult to establish conclusively their structural effects on regional innovation networks. Focusing on the French cluster policy during the period 2005-2010, this study aims at evaluating how cluster policies influence the structure of local innovation networks following network topologies that may be beneficial for regional innovation. Based on a panel data of four periods and 94 NUTS3 French regions, we estimate spatial Durbin models, allowing us to identify direct, indirect and total effects of cluster policies. The results suggest that cluster policies can result in both positive and negative total effects on the structure of local innovation networks depending on regions' technological specialisation. Beyond the heterogeneous effects, the results also highlight that cluster policies may lead to a regional competition for the strengthening of innovation networks. This finding echoed previous research pointing out the possible 'beggar-thy-neighbour' effects of cluster policies.
\end{abstract}

\section{Keywords:}

Cluster, Regional innovation, Innovation network, Policy evaluation

JEL codes:

L52, O33, R58 


\title{
Effects of cluster policies on regional innovation networks: Evidence from France
}

\author{
Konan Alain N'Ghauran ${ }^{1, *}$, Corinne Autant-Bernard ${ }^{1}$ \\ ${ }^{1}$ Univ Lyon, UJM Saint-Etienne, CNRS, GATE L-SE UMR 5824, F-42023 Saint-Etienne, France \\ "Main author for correspondence. Email: nghauran@gate.cnrs.fr
}

\begin{abstract}
Despite the growing body of literature evaluating cluster policies, it still remains difficult to establish conclusively their structural effects on regional innovation networks. Focusing on the French cluster policy during the period 2005-2010, this study aims at evaluating how cluster policies influence the structure of local innovation networks following network topologies that may be beneficial for regional innovation. Based on a panel data of four periods and 94 NUTS3 French regions, we estimate spatial Durbin models, allowing us to identify direct, indirect and total effects of cluster policies. The results suggest that cluster policies can result in both positive and negative total effects on the structure of local innovation networks depending on regions' technological specialisation. Beyond the heterogeneous effects, the results also highlight that cluster policies may lead to a regional competition for the strengthening of innovation networks. This finding echoed previous research pointing out the possible 'beggar-thy-neighbour' effects of cluster policies.
\end{abstract}

Keywords. Cluster, Regional innovation, Innovation network, Policy evaluation

JEL codes. L52, O33, R58 


\section{Introduction}

The study of innovation processes has been carried out by many scholars from different academic fields. In the regional science literature, the regional innovation system (RIS) framework is one of the wellestablished frameworks for analysing innovation processes at the territorial level (Doloreux and Parto, 2005). This framework is based on the systemic view of innovation, which argues that actors do not innovate in isolation, but that they are embedded in complex innovation networks in which actors with diverse capabilities create and exchange knowledge. Accordingly, it is widely acknowledged that a region's innovative output is not only the result of actors' individual efforts but it is also strongly influenced by the quality and intensity of regional innovative networking (Doloreux, 2002; Graf and Henning, 2009). The recognition of the importance of interactions between innovation actors has greatly contributed to the development of public policies aiming at strengthening knowledge networks. Indeed, this change in perspective regarding innovation processes has extended the scope of innovation policies by moving policymakers from single-point interventions relating to individual research projects or companies to network interventions (Arnold and Boekholt, 2002).

Such interventions are referred to as innovation network policies and defined by Cunningham and Ramlogan (2016) as "measures aimed at promoting or sustaining the linkage of firms and/or knowledge producers where the activities concerned are centred on a specific technological or problem-oriented topic for the primary purpose of knowledge and information sharing". In this context, innovation network policies are justified, at least in part, by the insufficient and/or inefficient levels of linkage and knowledge exchange between organisations. They differ in this sense from traditional innovation policies, focused on the provision of research and development (R\&D) funding, which are generally based on the market failures argument. Although also providing funds for the implementation of R\&D projects, primarily collaborative projects, innovation network policies are intended to go further by tackling the systemic failures rather than just market failures, thus highlighting the significance of actors as well as the relationships between them. Such interventions are of crucial importance at the regional level since the set of relationships between actors constitute a relational capital allowing regions to act as innovative milieus (Camagni, 1995) and maintain a long-term competitiveness thanks to collective 
learning (Capello and Faggian, 2005). Aware of this, policymakers have, for several years now, supported measures to strengthen regional innovation networks and cluster policies have become an important component of their toolbox in this respect (Cunningham and Ramlogan, 2016; Uyarra and Ramlogan, 2016). As pointed by Cunningham and Ramlogan (2016), innovation network policies differ from clusters in that they are not necessarily geographically co-located; co-location is therefore the primary criterion differentiating innovation network policies from cluster policies. As innovation network policies, cluster policies are also expected to strengthen the structure of innovation networks, but especially at the territorial or regional level.

Although clusters are regarded as important instruments to strengthen regional innovation networks, most evaluations of cluster policies are focused on market failures (Falck et al., 2010; Nishimura et Okamuro, 2011a; Bellégo and Dortet-Bernadet, 2014; Brossard et Moussa, 2014; Braune et al., 2016). The effects of cluster policies on the structure of innovation networks have yet to be fully evaluated in the literature. In the debate to which extent public interventions are effective, the "additionality" question - i.e. the results that would not have been realised by the private sector without the public instrument, e.g. subsidies, tax credits, innovation network policies - takes a central place (Larosse, 2001). Following this additionality perspective, the cluster evaluation literature falls into three streams: input and output additionality, behavioural additionality and systemic additionality.

Looking at the input and output additionality of cluster policies, and more broadly of innovation network policies, is the most common form of evaluation undertaken in the literature (Sakakibara, 1997; Branstetter and Sakakibara, 2002; Hottenroot and Lopes-Bento, 2014; Bellégo and Dortet-Bernadet, 2014; Brossard et Moussa, 2014; Braune et al., 2016). This kind of assessment essentially consists in estimating additional inputs (primarily $R \& D$ expenditure and human capital) and comparing the outputs (economic growth, productivity, patents, etc.) of actors that received and did not receive support from clusters. This way of evaluating cluster policies seems to be a pure legacy of the linear innovation model in which innovation (output) is largely a straightforward outcome of research and development activities (input). This approach has therefore been criticised for being limited since regional innovation policies do not only aim at increasing the amount of resources that actors invest in innovation and/or their 
innovative outputs. As stated above, such interventions also aim at changing actors' behaviour by promoting and sustaining the linkage and knowledge exchange between them. In this vein, the Organisation for Economic Co-operation and Development (OECD) has recommended to consider behavioural additionality in econometric studies (Georghiou and Clarysse, 2006).

Thus, a growing literature is attempting to understand and evaluate the difference in actors' behaviour resulting from innovation network policies and cluster policies, i.e. the behavioural additionality of these policies (e.g. Clarysse et al., 2009; Falck et al., 2010; Nishimura and Okamuro, 2011b; Giuliani et al., 2016; Rothgang et al., 2017; Töpfer et al., 2017)ํ. The main goal of this literature is to test the ability of policy interventions to stimulate learning processes that result in changes in actors' behaviour. In the specific case of cluster policies or regional innovation policies, scholars explore organisations' collaboration patterns (Antonioli et al., 2014; Caloffi et al., 2015; Caloffi et al., 2017), thus considering the latter as the units of analysis. Although such micro level analyses provide insightful results on how organisations change their behaviour when participating in innovation network policies, they do not provide a macroeconomic overview of how innovation networks are structured following the microeconomic changes observed in the behaviour of organisations. Assessing the overall structure of innovation networks is all the more important given that the sum of individual additional results cannot assess appropriately the emergence of system effects (Bellandi and Caloffi, 2010).

Questions regarding additionality at the network and/or regional level are tackled in a third strand of the cluster evaluation literature (e.g. Bellandi and Caloffi, 2010; He et al., 2013; Ter Wal, 2013; Rothgang et al. 2017; Töpfer et al., 2017; Lucena-Piquero and Vicente, 2019). Studies from this strand of research start from the premise that innovation network policies are primarily designed to strengthen innovation networks and build on the theoretical work on the link between network structures and innovation performance. In this vein, scholars have drawn attention to how the whole structure of innovation

\footnotetext{
${ }^{1}$ Several different terms are used in the literature to refer to behavioural additionality (collaboration additionality, network additionality, etc.); this can be particularly confusing for readers that are not familiar with this literature. No matter what term is used to describe behavioural additionality, they all have their roots in the Buisseret et al. (1995) definition which made it clear that behavioural additionality covers changes in organisation/actor behaviour that result from public support. Nevertheless, despite the growing use of the concept of behavioural additionality in the cluster literature, the definition and theorisation of the concept still needs further work (Gök and Edler, 2012) to allow for meaningful comparisons and the development of evidence-based policy recommendations.
} 
networks evolves as a result of innovation network policies. Larosse (2001) refers to this kind of additionality as systemic additionality to stress the fact that innovation network policies aim at changing the system. Despite the relevance of this type of evaluation, systemic additionality is rarely addressed in the literature. The most recent and relevant works in this area are essentially based on descriptive analyses of social networks ${ }^{2}$ (Rothgang et $a l$. 2017; Töpfer et al., 2017; Lucena-Piquero and Vicente, 2019) or on qualitative analyses (He et al., 2013). Moreover, most of these studies rely on information about the collaborative projects supported by clusters. Since the key issue is to estimate the "additionality" of cluster policies, we claim that using such data source is not relevant to assess systemic additionality because the whole structure of the systems or innovation networks is not considered.

This paper aims to contribute to this third strand of literature by filling these gaps. Compared to previous studies, instead of describing innovation networks directly from projects supported within clusters, we rely on patent data to get closer to the actual structure of local (NUTS3) innovation networks. Then, we empirically assess the effects of cluster policy on those networks - i.e. the changes in the structure of innovation networks resulting from the policy -. We focus on the French cluster policy over the period 2005-2010. Based on a literature review, we summarised the structural changes under scrutiny in four network topologies: embeddedness or connectivity, efficiency, resilience and geographical anchoring. Our empirical strategy relies on spatial Durbin models applied to panel data of four periods and 94 NUTS3 French regions (called departments). We also tested for effect heterogeneity across departments according to their level of technological specialisation. Our econometric specification allows us to identify three types of cluster policy effects: direct or locally bounded, indirect or associatedneighbourhood spatial effects and the total cumulative effect resulting from the direct and indirect effects. Our results indicate a positive total effect of the French cluster policy on the efficiency of local innovation networks by increasing the small-world nature of those networks, especially in the case of highly specialised departments. However, regarding network resilience, we found an adverse effect of the policy on the structure of innovation networks in low specialised departments. In those departments,

\footnotetext{
${ }^{2}$ In this strand of literature, innovation networks are usually proxied by social networks (in which nodes can represent inventors, organisations, etc.).
} 
the policy has contributed to strengthen collaboration but mostly between central actors of the networks, leaving aside peripheral actors. Finally, we found no significant total effects on network embeddedness and the regional anchoring of networks even though some direct positive effects have been observed. This suggests the existence of territorial competition resulting from cluster policies. Besides contributing to close a research gap, this paper also has a rather interesting and meaningful implication for policy makers. It does not only show evidence that cluster policies can positively or negatively affect the structure of innovation networks depending on the regional level of specialisation, but also suggests that the strengthening of innovation networks in some territories as a result of cluster policies could be to the detriment of other territories.

The remainder of the paper is organised as follows. Section 2 begins the analysis with a literature review on the characterisation of innovation networks and derives our research questions. Section 3 describes the data and explains the estimation techniques. Section 4 discusses the findings and interprets the structural effects of the French Cluster policy. A final section concludes and derives policy recommendations.

\section{Literature review and research questions}

As outlined in the introduction, by fostering relationships between actors, cluster policies aim at providing a strong social/relational capital allowing regions to act as innovative milieus (Camagni, 1995). But the real challenge is how to measure such a social capital, especially when it is considered as a collective resource (Coleman, 1990). Starting from a conceptualisation of social capital at the local level, Galaso (2017) proposes to identify local social capital with the network topologies that may positively influence local performances. While making this proposition, Galaso (2017) points out that local social capital is not the network itself, but certain topological properties of the local network that may facilitate the appearance of positive externalities. Following this approach, we provide a literature review of network topologies that may prove to be beneficial for regional innovation and set out our research questions. 


\subsection{Network topologies for regional innovation}

The literature on the geography of innovation has embraced the view that a high concentration of actors, even belonging to the same sector, in an area is not enough to explain the innovative capacity of that area (Capello and Faggian, 2005). For such an area to be innovative, collective learning is a prerequisite since it implies a high level of cultural proximity (sense of belonging, interaction capacity and common values) among local actors (Capello and Faggian, 2005). This cultural proximity is reflected in a strong network embeddedness, which is the extent to which actors are linked to third parties in the network (Raub and Weesie, 1990). Network embeddedness can be assessed through the overall network connectivity which is expressed as the proportion of node pairs in a network that can reach one another thanks to the existence of a network path between them (Ter Wal, 2013). Connectivity is also known to facilitate knowledge spillovers since a network with high connectivity allows knowledge to flow through direct and indirect linkages (Nooteboom and Klein-Woolthuis, 2005). Wanzenböck et al. (2019) provide empirical evidence of the positive effect of R\&D network embeddedness on innovation performances at the EU level. Accordingly, the first research question is as follows:

\section{Q1. Do cluster policies increase the embeddedness in local innovation networks?}

As discussed above, collective learning is a prerequisite for innovative regions and takes place in networks with high connectivity. While such networks can make regions more innovative, they are not necessarily efficient. Indeed, even though networks with high connectivity allow knowledge to flow, an efficient knowledge circulation depends on the geodesic distance between actors in the network. The larger the geodesic distance between any two actors, the weaker the linkage between these actors, resulting in a smaller likelihood that they will interact with each other. The geodesic distance has, therefore, strong implications for trust building, knowledge transfer and spillovers diffusion. A large part of the literature analysing the link between innovation performance and network structures identify small-world networks as efficient networks for innovation production and diffusion (Kogut and Walker, 2001; Uzzi and Spiro, 2005; Fleming et al., 2007; Schilling and Phelps, 2007). The combination of the two main properties of such networks (high clustering and low average path length; Watts and Strogatz, 1998) is said to boost innovation. A small-world network with a high clustering coefficient (nodes 
sharing common partners tend also to be directly connected together) and a short path length (average social distance between any pair of nodes) combines the advantages of efficiency and embeddedness. Fleming et al. (2007) have empirically demonstrated the positive effects of short path length and a high clustering coefficient on regional innovativeness. However, it is worth noting that the literature reports divergent but complementary views about clustering since it implies redundant links. While the Coleman's closure argument stresses the importance of redundant links because they facilitate trust and reduce opportunism (Coleman 1988; 1990), Burt (1992) points out the advantages of structural holes which allow actors to have access to valuable and new resources. We therefore consider that the absence of redundant links due to a low level of clustering between actors is not a systematic evidence of network inefficiency. Therefore, the second research question is stated as follows:

\section{Q2. Do cluster policies reinforce the efficiency of local innovation networks?}

Most of the previous studies exploring the relation between network structural properties and regional innovation focused on innovation performance considering innovation production and diffusion. However, in a context characterised by faster technological cycles and increasing turbulence in the economic environment, efficient innovation networks can also be sensitive to external shocks and exhibit fragility properties (Crespo et al., 2014). Network resilience therefore appears as an important feature allowing innovative regions to regulate the trade-off between path dependency and adaptability (Pike et al., 2010; Simmie and Martin, 2010). In this vein, Crespo et al. (2014) argued that innovation networks can exhibit a resilience property in presence of hierarchy (existence of a core/periphery structure in the network) and disassortativity (tendency of weakly connected agents to create ties with highly connected agents). Hierarchical networks allow to set up compatibility and interoperability among the different components of the network in order to reduce system dysfunctions and enhance knowledge diffusion within the network. Disassortative networks limit the redundancy of knowledge flows and also allow the exploration or exploitation of new ideas emerging from either the core or the periphery on the network. The third research question is therefore formulated as:

\section{Q3. Do cluster policies reinforce the resilience of local innovation networks?}


During the recent years, several studies have investigated the effects of network geographical anchoring on innovation. This literature mainly focuses on the influence of network openness on regional performance and overall, findings do not give primacy to any form of relation either distant or local since both have advantages for regional innovation. On the one hand, some authors claim that distant relations have a positive influence in regional innovative performance because they bring new ideas into the region to avoid redundancy and lock-in (Bathelt et al., 2004; Breschi and Lenzi, 2016). On the other hand, other studies (Boschma 2005; D'Este et al., 2013) present evidence suggesting that local collaborations facilitate and strengthen network embeddedness especially when local actors share a common knowledge base with diverse but complementary capabilities. To sum up, the findings from this strand of literature indicate that local and distant relationships have a complementary role in enhancing regional innovation. Broekel (2012) and De Noni et al. (2017) summarised this by pointing that a balance between local and distant collaboration is required to support regional innovation. Accordingly, the fourth and last research question can be stated:

Q4: Do cluster policies reinforce and expand the geographical anchoring of local innovation networks?

We sought to answer these four questions using the case of the French cluster policy.

\subsection{French cluster policy}

In the early 2000s, innovation policy has become a major public concern and French government officials have nurtured the ambition to create a better combination than in the past, of innovation and industry within territories. The period 1999 to 2008 saw the development of policy instruments designed on the one hand to develop cooperation between actors and on the other hand to enhance the valorisation of public research (Lallement and Harfi, 2016). It is in this context that the French cluster policy was launched in 2005 to raise the innovative capacity of France. According to an official definition, a (French) cluster "brings together large and small firms, research laboratories and educational establishments, all working together in a specific region to develop synergies and cooperative efforts". French clusters are intended to actively support networking between firms, universities and research organisations mainly at the regional (NUTS2) level even though clusters were also encouraged over 
time to increase networking between their members and actors from others regions. From those networking activities come out collaborative R\&D projects and then innovation and regional growth. The French cluster policy therefore appears an interesting and relevant case study to address our research questions.

From 2005 to 2010, 71 competitiveness clusters from various fields (energy, mechanics, aerospace, transport, ICTs, health, environment, ecotechnology, etc.) have been supported by the French authorities. The State support for clusters mainly takes the form of (i) a partial financing of cluster governance structures, alongside local authorities and members (public research organisations and firms), and (ii) the granting of financial aids to collaborative R\&D projects coming out of clusters. Between 2005 and 2013, 1,313 collaborative R\&D projects endorsed by clusters received public financing of $€ 2.37$ billion, including more than $€ 1.45$ billion granted by the French State through the Single Inter-Ministry Fund (FUI). Clusters are also financed from membership fees. In return, members receive support from the cluster in terms of training and assistance in setting up collaborative R\&D projects especially in partners' searching and networking.

\section{Data and methodology}

As mentioned in the previous sections, this study aims at assessing the (additional) effects of cluster policies on the structure of local innovation networks. This requires to find first external-to-the-policy data in order to define the local innovation networks and then to rely on relevant network measures characterising the four topologies of interest.

\subsection{Data}

The relational capital of a territory is an intangible asset that cannot be directly measured (Capello and Faggian, 2005). Recent empirical advancements in the geography of innovation literature, however, have shown that patent data allow us to measure, although not exhaustively, an important component of relational capital which is cooperation among inventors (Ter Wal and Boschma, 2009). These contributions suggest that co-inventorship networks can be considered as a proxy for local networks of collective learning (Ter Wal, 2013). Following this research line, we propose to reconstruct co- 
inventorship networks based on patent data to proxy innovation networks. Innovation networks were therefore based on patent applications submitted to the French patent office (INPI) over the period 20022013. We used a three-year lag between the beginning of R\&D projects and patent applications ${ }^{3}$. By doing this, we considered that patent applications submitted between 2002 and 2013 result from R\&D projects that started during the 1999-2010 period. This time span was broken down into four three-year periods around 2005 i.e., two pre-policy periods: 1999-2001, 2002-2004 and two post-policy periods 2005-2007, 2008-2010.

The local innovation networks for 94 NUTS3-regions (so called departments) were defined during each of these periods. This results in a set of $376(94 \times 4)$ networks. Innovation networks are portrayed using nodes which represent inventors and edges connect pairs of nodes which are the co-inventors for at least one patent. Isolated nodes are inventors which are not involved in any co-invention. The local innovation network of each department was built using all the patents involving at least one inventor belonging to the department; therefore, it can be seen as an aggregation of the ego-networks of local inventors. This implies that local innovation networks are constituted by local but also non-local inventors ${ }^{4}$. If present in a local innovation network, non-local inventors have at least one direct connection to at least one local inventor (as illustrated in Figure 1).

\section{Figure 1 Local innovation network}

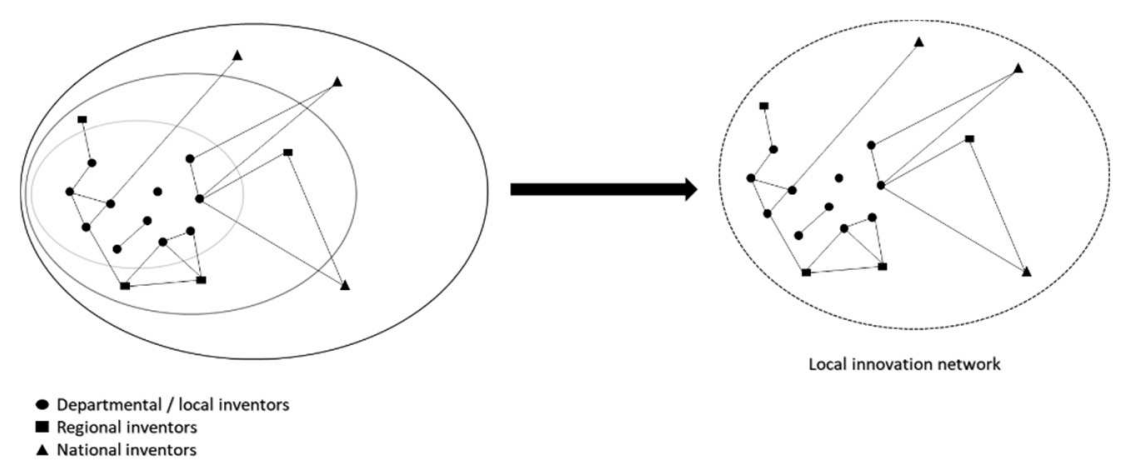

\footnotetext{
${ }^{3}$ The choice of this three-year lag is justified by the average duration of R\&D projects supported by clusters through the FUI, which is one of the main instruments for financing collaborative R\&D projects from French clusters.

${ }^{4}$ The inventor-disambiguated patent data we relied on - which are provided by the French patent office - only include applicants and inventors with a French address. The dataset is freely accessible at https://data.enseignementsup-recherche.gouv.fr/explore/dataset/fr-esr-brevets-france-inpi-oeb
} 
Cluster members are unevenly distributed throughout the country. We therefore defined the treatment intensity for each department as the ratio of the number of cluster members located in the department to the number of establishments involved in $R \& D$ activities and also located in the department. Since the policy started in 2005, the treatment intensity is zero for all the departments during the pre-treatment periods (1999-2001 and 2002-2004). During the first post-treatment period (2005-2007), the average treatment intensity per department was about $8.8 \%$, meaning that $8.8 \%$ of establishments involved in R\&D activities in the French departments were cluster members. That average has almost doubled (14.6\%) over the second post-treatment period (2008-2010). Not surprisingly, and as shown in Figure 2, these averages hide a strong heterogeneity between departments even though there has been little change in the spatial distribution of cluster members between both periods.

Some departments have a share of cluster members - treatment intensity - well above the averages; this is particularly the case for departments from the western (e.g. Finistère, Maine-et-Loire, LoireAtlantique), southern (e.g. Alpes-Maritimes, Haute-Garonne), and eastern (e.g. Haute-Savoie, Doubs, Vosges) parts of the country. Three of them stand out for being in the top 3 on both periods: HauteSavoie, Doubs and Vosges. These regions are known to be medium-sized departments with a high industrial specialisation. Haute-Savoie hosts the Arve Valley whose expertise in precision machining has been developed from the region's clock and watch making industry during the $19^{\text {th }}$ century. The Arve Valley's expertise is nowadays recognised throughout the world and precision machining in the Haute-Savoie department accounts for 30\% of its GDP and 70\% of total French sales for this sector. Regarding the Doubs department, since the $17^{\text {th }}$ century it has been shaped by the watchmaking industry thanks to an internationally recognised know-how in the various stages of watch manufacture. Following the watchmaking crisis of the 1970s and 1980s, the department has gradually diversified its industrial base towards microtechnology and is now considered as one of the leading French territories in the field of microengineering. Finally, the Vosges, often referred to as the "Wood Valley" is the leading French department for the volume of wood production (over 1 million $\mathrm{m}^{3}$ per year). The wood industry has always occupied an important place in the local economy and the department is home to a complete wood-based industry, ranging from timber harvesting to primary and secondary manufacturing 
(construction and high-end furnishings). To date, the department hosts more than 1,000 establishments and 13,000 jobs in the wood industry as well as the only public engineering school in France specialising in technologies related to wood and natural fibres.

Most of the other departments having a high treatment intensity are also characterised by a certain level of industrial specialisation, although in smaller extent than those already mentioned. This descriptive analysis confirms the close link between the treatment intensity and territorial specialisation.

Figure 2 Treatment intensity (during the post-treatment periods)

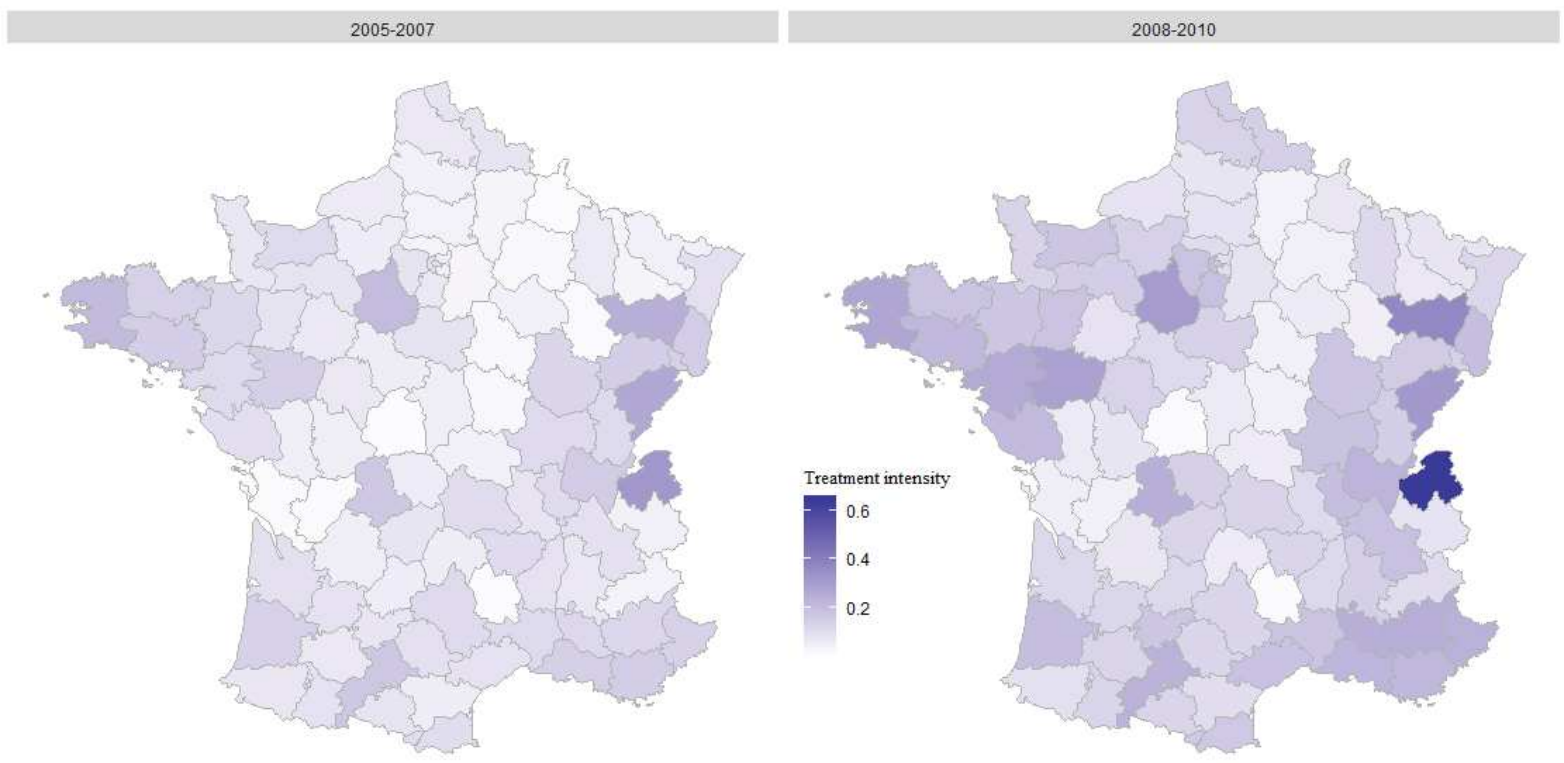

After defining the local innovation networks and the treatment variable, a set of ten outcome variables were selected in order to characterise the four network topologies of interest, namely embeddedness, efficiency, resilience and geographical anchoring. The selection of such a number of indicators or outcome variables is explained by the fact that the network topologies under scrutiny are complex and cannot be consistently assessed on the basis of a single network indicator. Therefore, for each network topology, at least two outcome variables are used for its characterisation. The selection of those variables is based on how well they describe the selected topologies on the one hand, and how well-established they are in the theoretical and empirical literature on the other (Table 1).

All these outcome variables were computed for the 376 local innovation networks. This yields a panel data set that spans four periods. 
Two important methodological issues must be discussed here. Firstly, most studies on innovation or even social networks focus on the network's main component to provide network indicators. This is because most of these indicators require direct or indirect connexions between nodes to be computed. This is for instance the case for the average path length ratio. The focus on the main component induce an important bias (in our case the main component of the 94 local networks often gathers less than $10 \%$ of the total number of nodes). To overcome this difficulty, we only considered and averaged the lengths of the existing paths and set the mean degree in the neighbourhood of isolated nodes to zero (Crespo et al. 2014). This allows us to take into account all the information regarding the local networks.

In addition, network indicators could be very sensitive to the network size. This is all the more important to control for this size effect when it comes to compare the properties of networks involving a very different number of actors. To this aim, as soon as size matters, we define our network indicators as a ratio of the observed value in the observed network to the value obtained for a random network of equal size. 
Table 1 Outcome variables 5

\begin{tabular}{|c|c|c|c|c|}
\hline Network topologies & Outcome variables & Description & $\begin{array}{l}\text { Theoretical } \\
\text { references }\end{array}$ & $\begin{array}{l}\text { Empirical } \\
\text { references }\end{array}$ \\
\hline \multirow[t]{2}{*}{ 1-Embeddedness } & Density & $\begin{array}{l}\text { Density represents the proportion of possible relationships in } \\
\text { the network that are actually present. This is the ratio of the } \\
\text { number of edges to the number of possible edges. } \\
\text { It is a well-established statistic in the literature and high levels } \\
\text { of density are supposed to generate a belonging/camaraderie } \\
\text { collective feeling in social networks. This may lead to a } \\
\text { reduction of the risk of adopting collaborative solutions thanks } \\
\text { to an increase in trust and cooperation. } \\
\text { Moreover, information in dense networks can flow more easily } \\
\text { than in sparse or fragmented networks. }\end{array}$ & $\begin{array}{l}\text { Wasserman and } \\
\text { Faust (1994) }\end{array}$ & $\begin{array}{l}\text { Giuliani et al., } \\
2016\end{array}$ \\
\hline & Fragmentation index & $\begin{array}{l}\text { Fragmentation occurs when two nodes belong to different, } \\
\text { unconnected components of the network. The fragmentation } \\
\text { index is the ratio of the number of components to the number } \\
\text { of nodes. } \\
\text { It indicates the degree to which some nodes are disconnected } \\
\text { from the network and is defined as the proportion of node pairs } \\
\text { that cannot reach each other. }\end{array}$ & $\begin{array}{l}\text { Wasserman and } \\
\text { Faust (1994) }\end{array}$ & $\begin{array}{l}\text { Giuliani et al., } \\
2016 \\
\text { Ter Wal, } 2013\end{array}$ \\
\hline
\end{tabular}

${ }^{5}$ For more details on the mathematical formulation of the variables, the reader is referred to the cited literature and references therein. 


\begin{tabular}{|c|c|c|c|c|}
\hline Network topologies & Outcome variables & Description & $\begin{array}{l}\text { Theoretical } \\
\text { references }\end{array}$ & $\begin{array}{l}\text { Empirical } \\
\text { references }\end{array}$ \\
\hline & $\begin{array}{l}\text { Share of the } \\
\text { network's main } \\
\text { component }\end{array}$ & $\begin{array}{l}\text { The largest component of connected nodes in a network is } \\
\text { referred to as the main component. The share of the network's } \\
\text { main component is the ratio of number of nodes in the main } \\
\text { component to the total number of nodes in the network. } \\
\text { This is the percentage of nodes present in the main or largest } \\
\text { component. The higher the number of nodes present in the } \\
\text { main component, the more a collective learning process is } \\
\text { assumed to take place within the network. }\end{array}$ & $\begin{array}{l}\text { Wasserman and } \\
\text { Faust (1994) }\end{array}$ & $\begin{array}{l}\text { Cantner and Graf } \\
(2006) \\
\text { Casper (2007) } \\
\text { Fleming and } \\
\text { Frenken (2007) } \\
\text { Ter Wal (2013) }\end{array}$ \\
\hline 2-Efficiency & $\begin{array}{l}\text { Clustering coefficient } \\
\text { (ratio) }\end{array}$ & $\begin{array}{l}\text { The large clustering coefficient displayed by small-world } \\
\text { networks describes a tendency of closure i.e. nodes that share } \\
\text { neighbours are often also directly connected to each other. It } \\
\text { is widely acknowledged that network closure generates trust } \\
\text { which in turn promotes collaboration and facilitates risk } \\
\text { sharing, resource pooling, and information diffusion. } \\
\text { The clustering coefficient ratio is defined as the ratio of the } \\
\text { observed clustering coefficient to the clustering coefficient of } \\
\text { a random network of equal size and density. It indicates the } \\
\text { extent to which the observed clustering coefficient differs from } \\
\text { the value expected in comparable random network. }\end{array}$ & $\begin{array}{l}\text { Granovetter } \\
(1985) \\
\text { Coleman (1988) } \\
\text { Uzzi and Spiro } \\
(2005)\end{array}$ & Ter Wal (2013) \\
\hline
\end{tabular}




\begin{tabular}{|c|c|c|c|c|}
\hline Network topologies & Outcome variables & Description & $\begin{array}{l}\text { Theoretical } \\
\text { references }\end{array}$ & $\begin{array}{l}\text { Empirical } \\
\text { references }\end{array}$ \\
\hline & $\begin{array}{l}\text { Average Path length } \\
\text { (ratio) }\end{array}$ & $\begin{array}{l}\text { Low path length increases network connectivity, and so it } \\
\text { makes easier knowledge circulation and transmission. A } \\
\text { decrease in a network's average path length increases network } \\
\text { connectivity which in turn can improve network nodes } \\
\text { performance. } \\
\text { The path length ratio is defined as the ratio of the observed } \\
\text { average path length to the average path length of a random } \\
\text { network of equal size and density. It indicates the extent to } \\
\text { which the observed average path length differs from the value } \\
\text { expected in comparable random network. }\end{array}$ & $\begin{array}{l}\text { Uzzi and Spiro } \\
(2005)\end{array}$ & $\begin{array}{l}\text { Fleming et al. } \\
\text { (2007) } \\
\text { Ter Wal (2013) }\end{array}$ \\
\hline 3-Resilience & Hierarchy & $\begin{array}{l}\text { The presence of hierarchy in a network is reflected by an } \\
\text { unequal distribution of degrees. Crespo et al. (2015) argued } \\
\text { that in hierarchical networks, core actors have enough power } \\
\text { to coordinate the whole network and lead the systemic } \\
\text { technological process while peripheral ones can bring } \\
\text { complementary modules to that process. } \\
\text { The level of network hierarchy is considered as the slope of } \\
\text { the degree distribution, i.e. the relation between nodes degree } \\
\text { and their rank position. }\end{array}$ & $\begin{array}{l}\text { Borgatti } \\
\text { and Everett (1999) }\end{array}$ & $\begin{array}{l}\text { Crespo et al. } \\
(2014 ; 2015)\end{array}$ \\
\hline
\end{tabular}




\begin{tabular}{|c|c|c|c|c|}
\hline Network topologies & Outcome variables & Description & $\begin{array}{l}\text { Theoretical } \\
\text { references }\end{array}$ & $\begin{array}{l}\text { Empirical } \\
\text { references }\end{array}$ \\
\hline & Assortativity & $\begin{array}{l}\text { Hierarchical networks are relevant structures mainly for } \\
\text { network coordination. However, even though it is crucial to } \\
\text { have key actors coordinating a local innovation network, the } \\
\text { degree of openness among the core and the periphery of the } \\
\text { network also matters. Crespo et al. (2014) point out the } \\
\text { necessity for the different hierarchical levels to be connected } \\
\text { in order to avoid redundancy of knowledge flow and also to } \\
\text { allow the exploration or exploitation of new ideas from either } \\
\text { the core or the periphery. They referred to this tendency of } \\
\text { nodes in a network to connect with other nodes as assortativity } \\
\text { (also called homophily). } \\
\text { A network is assortative when nodes are preferentially } \\
\text { connected with other nodes that have a similar degree, i.e. } \\
\text { high-degree nodes tend to interact with high-degree nodes, and } \\
\text { low-degree nodes with low-degree nodes. On the contrary, a } \\
\text { network is disassortative when high-degree nodes tend to } \\
\text { interact with low-degree nodes, and conversely. } \\
\text { The level of assortativity or disassortativity of networks is } \\
\text { reflected by the degree correlation: it is the slope of the relation } \\
\text { between nodes' degree and the mean degree of their local } \\
\text { neighbourhood. }\end{array}$ & $\begin{array}{l}\text { McPherson et al. } \\
\text { (2001) }\end{array}$ & $\begin{array}{l}\text { Crespo et al. } \\
(2014 ; 2015)\end{array}$ \\
\hline
\end{tabular}




\begin{tabular}{|l|l|l|l|l|}
\hline Network topologies & Outcome variables & Description & $\begin{array}{l}\text { Theoretical } \\
\text { references }\end{array}$ & $\begin{array}{l}\text { Empirical } \\
\text { references }\end{array}$ \\
\hline \multirow{4}{*}{$\begin{array}{l}\text { 4-Geographical } \\
\text { anchoring }\end{array}$} & Share of local links & $\begin{array}{l}\text { This is the ratio of the number of edges among local (NUTS3) } \\
\text { inventors to the number of edges in the network. } \\
\text { This indicates the strengthening the local anchoring of the } \\
\text { network. }\end{array}$ & Boschma (2005) & Ter Wal (2013) \\
\hline $\begin{array}{lll}\text { Share of regional } \\
\text { links }\end{array}$ & $\begin{array}{l}\text { This is the ratio of the number of edges between local } \\
\text { (NUTS3) and regional (NUTS2) inventors to the number of } \\
\text { edges in the network. } \\
\text { This indicates the degree of openness of the network towards } \\
\text { regional actors. }\end{array}$ & Ter Wal (2013) \\
\hline & $\begin{array}{l}\text { Share of national } \\
\text { links }\end{array}$ & $\begin{array}{l}\text { This is the ratio of the number of edges between local } \\
\text { (NUTS3) and national (neither local, nor regional) inventors } \\
\text { to the number of edges in the network. } \\
\text { This indicates the degree of openness of the network towards } \\
\text { national actors. }\end{array}$ & Boschma (2005) \\
\hline
\end{tabular}


Quartiles $\square$ Q1 $\square$ Q2 $\square$ Q3 $\square$ Q4
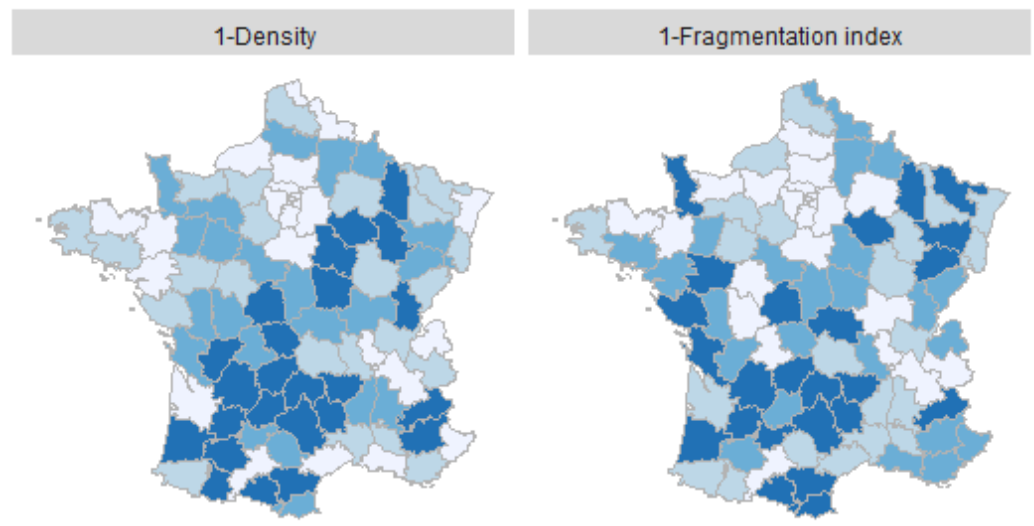

1-Share of network's main component

2-Average path length (ratio)

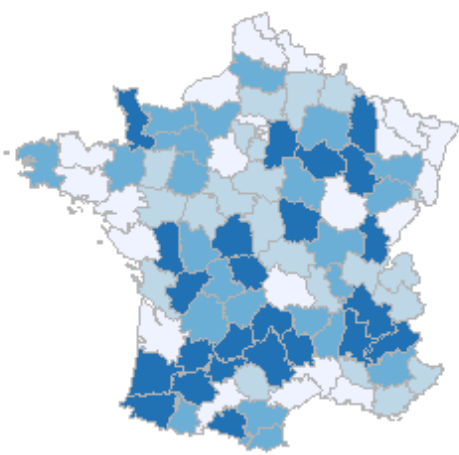

3-Assortativity

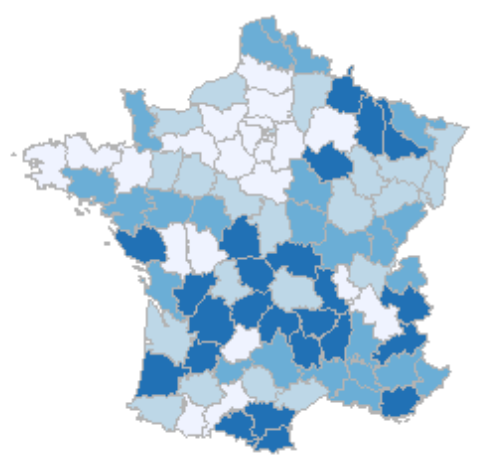

3-Hierarchy

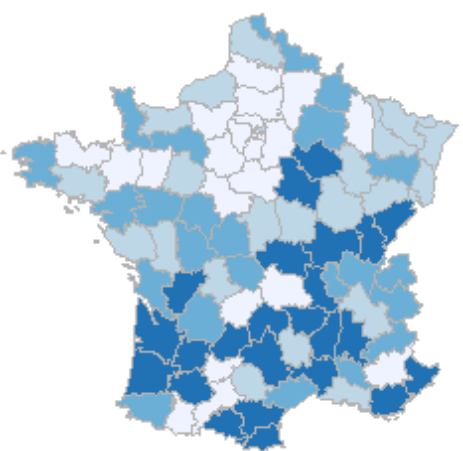

4-Share of local links

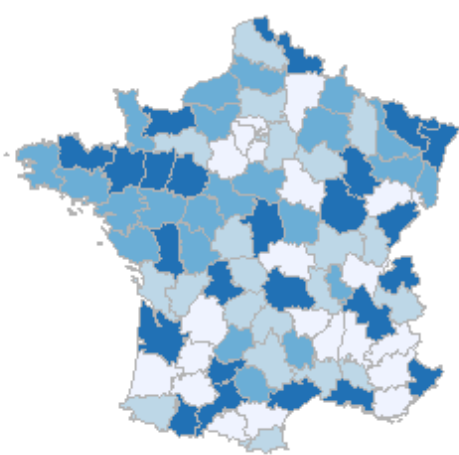

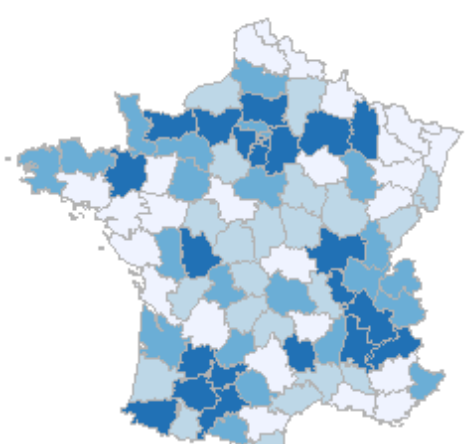

4-Share of national links

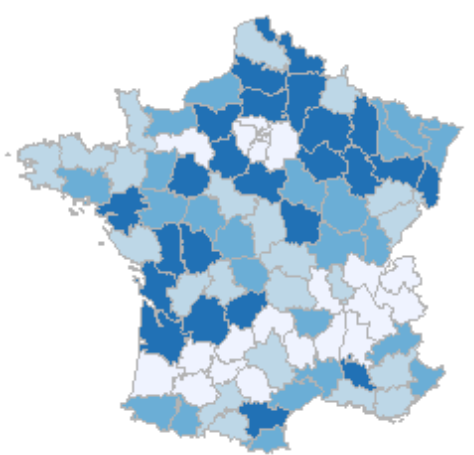

2-Clustering coefficient (ratio)

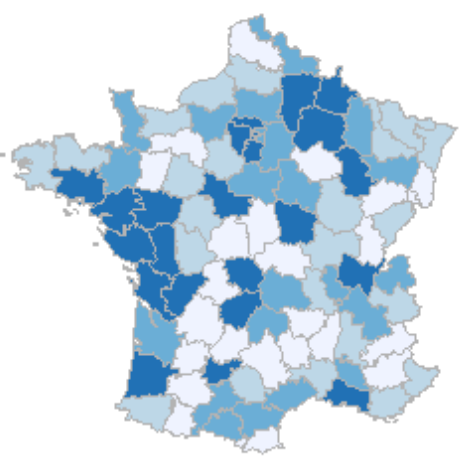

4-Share of regional links

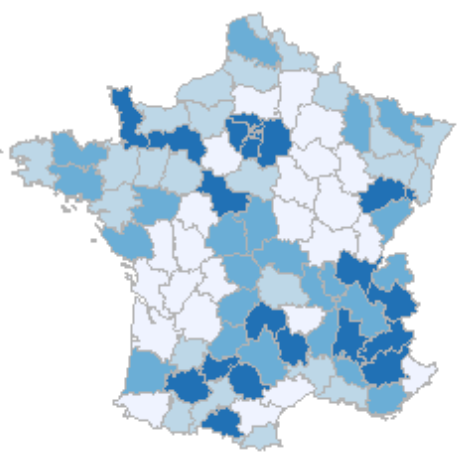


Figure 3 shows the spatial distribution of the outcome variables, averaged over the pre-treatment periods. Looking at the variables characterising network embeddedness (the first topology - 1), we can see that most of the dense innovation networks with a large main component were fragmented before the implementation of the cluster policy. The few exceptions are Haute-Vienne, Vienne, Saône-et-Loire and Somme which therefore could be considered as some of the most connected local innovation networks since they were also dense but less fragmented compared to the other networks. The tendency for dense networks to be fragmented could be explained by the existence of several technological areas within departments; each area being developed by different communities of actors. In this vein, cluster policy implemented in such diversified departments is likely to strengthen network fragmentation, especially with multi-thematic clusters.

Regarding the efficiency (second topology - 2) of local innovation networks during the pre-policy periods, it turns out that most of the small-world networks (i.e. networks characterised by high clustering coefficient and low average path length) were essentially those of west coast departments, namely Morbihan, Loire-Atlantique, Vendée and Charente-Maritime. Although there were also other departments (Ardennes, Bouches-du-Rhône, etc.) having the "small-worldness" property, small-world networks were not the most prevalent situation in French departments even in innovative territories such as the Paris area, Rhône and Haute-Garonne. Within innovation networks from those departments, the high level of clustering was very often coupled with a high average path length. By reducing path length, the cluster policy would make local innovation networks more efficient.

Furthermore, during the pre-policy periods, local innovation networks were also not resilient to the extent that as hierarchical structure was very often coupled with assortativity (third topology -3 ). Therefore, even though there were core actors able to coordinate local innovation networks, those actors tended to collaborate with each other. There were, of course, some exceptions, mainly among small to medium-sized departments such as Lot, Finistère, Marne, Orne, and Vienne. It is worth noting the growing and innovative department that is Rhône was one of these exceptions.

Finally, two main patterns are seen regarding the geographical anchoring (fourth topology -4 ) of innovation before the implementation of the French cluster policy. On the one hand, one can notice the 
central position of the Paris area especially the NUTS2-region Île-de-France. Actors from this region strongly interact with each other and also act as key partners for actors from neighbouring regions. Thus, departments close to Île-de-France tended to have a high share of national links and low level of regional or local links. On the other hand, departments with high shares of interaction at the local (NUTS3) and regional (NUTS2) levels were clustered in space: the northwest part of the country for local links and southeast for regional links. Such spatial clustering suggests the presence of interdependencies between innovation networks.

\subsection{Model}

The purpose of this study is to evaluate the effects of cluster policies (treatment) on the structure of local innovation networks (outcome variables). Conventional econometric models used to analyse crosssectional and panel data assume that statistical units are independent of one another. Since local innovation networks can involve non-local actors, we acknowledge that there is a systematic dependency between departments with respect to the structure of their innovation network. Spatial econometrics provide a natural tool to investigate such interdependencies. Empirical models from the spatial econometrics' literature deal with three different types of interactions (Manski, 1993; Elhorst, 2010):

— endogenous interaction, when the dependant variable of an agent or a geographical area depends on the dependant variables of its neighbours;

- exogenous interaction, when the dependant variable of an agent or a geographical area depends on the observable characteristics (independent variables) of its neighbours;

— spatial dependencies in the residuals due to unobserved characteristics.

A full model with the three types of interactions can take the form:

$$
\begin{gathered}
Y=\alpha \iota_{N}+\rho W Y+X \beta+W X \theta+u, \\
u=\lambda W u+\varepsilon
\end{gathered}
$$

We assume that the error term $\varepsilon$ follows a multivariate normal distribution of with a mean of zero and a variance of $\sigma^{2} I_{n}$, where $I_{N}$ is an $N \times N$ identity matrix. $\beta$ is the vector of parameters associated to each 
explanatory (treatment and control) variable, $\rho$ measures the endogenous interaction effects (referred to as spatial autoregressive coefficient) and $\theta$ the exogenous interaction effects. $\lambda$ captures the spatial correlation effect of errors known as spatial autocorrelation coefficient. Interdependencies are introduced in the model through $W$, an $N \times N$ nonnegative spatial weight matrix based on contiguity of the $N$ departments. Non-zero elements in the $i$ th row and the $j$ th column of $W$ indicate that department $i$ and $j$ are neighbours; the main diagonal elements are zero and rows are normalised so elements of each row sum to unity. $\iota_{N}$ is a constant term vector associated with the parameter $\alpha$ to accommodate situations where the vector $Y$ does not have a zero mean value. The three types of interactions are considered in this model through spatial lags terms for the outcome or dependent variable; the explanatory variables and the disturbances are respectively represented by $W Y, W X$ and $W u$. Even though there is no obstacle to estimating this full model (Equation [1]), most empirical studies consider one or two types of interactions ${ }^{6}$.

In order to choose which interaction(s), and therefore, which model has to be considered, LeSage (2014) suggested to regional scientists to consider only two models: the Spatial Durbin Error Model (SDEM) or the Spatial Durbin Model (SDM) since the other spatial models are special cases of either the SDEM model or the SDM model (see Elhorst, 2010 for a survey on spatial models specification).

$$
\begin{gathered}
Y=\alpha \iota_{N}+X \beta+W X \theta+u, \\
u=\lambda W u+\varepsilon \\
Y=\alpha \iota_{N}+\rho W Y+X \beta+W X \theta+\varepsilon
\end{gathered}
$$

Equations [2] and [3] respectively depict the SDEM and SDM models. As can be seen from both equations, the SDM model explicitly takes into account the endogenous and exogenous interactions, unlike the SDEM model which considers spatial correlation of the covariates and the error term. LeSage

\footnotetext{
${ }^{6}$ Making the model identifiable actually requires one to assume that neighborhood matrices $W$ are not identical for all the three types of spatial interactions. The most common solution in the spatial econometrics literature consists in eliminating one of the three forms of spatial correlation represented by parameters $\rho, \theta$ and $\lambda$.
} 
(2014) recommended to use a SDEM model when the research question reflects local spillovers, i.e. a situation in which one can assume that endogenous interaction is not present. Given the substantive aspects of our research questions as well as the structure of our data, this is not a plausible assumption. Indeed, local innovation networks involve both local and non-local actors, implying a systematic interdependence in the structure on innovation networks from different areas. In this contest, we are in the case of global spillovers and, as argued by LeSage (2014), the most relevant spatial model to choose is the SDM model ${ }^{7}$. Moreover, though the error term in Equation [3] could be further divided into spatially structured and random errors, therefore taking the form of Equation [1], ignoring spatial dependence in the disturbances, if present, will only cause a loss of efficiency in the estimates which will remain unbiased and consistent (LeSage and Pace, 2009; Elhorst, 2014a). Besides this empirical motivation, the choice of a SDM model is also theoretically relevant in that previous research has found that an effective way to reduce omitted variable bias is to estimate a spatial Durbin models (AutantBernard and LeSage, 2011; Fingleton and Le Gallo, 2012).

We therefore consider a spatial panel Durbin model specified as:

$$
Y_{i t}=\alpha \iota_{N}+\rho \sum_{j=1}^{N} W_{i j} Y_{j t}+X_{i t-1} \beta+\sum_{j=1}^{N} W_{i j} X_{i j t-1} \theta+\varepsilon_{i t}
$$

where $i$ is an index for the cross-sectional dimension (spatial units), with $i=1 ; \ldots ; N$, and $t$ is an index for the time dimension (time periods), with $t=1 ; \ldots ; T$. The subscript $t-1$ is introduced in all the regressors in order to make clear that they have been time-lagged one period. Equation [4] can be extended with department and time fixed effects:

$$
Y_{i t}=\mu_{i}+\lambda_{t}+\rho \sum_{j=1}^{N} W_{i j} Y_{j t}+X_{i t-1} \beta+\sum_{j=1}^{N} W_{i j} X_{i j t-1} \theta+\varepsilon_{i t}
$$

Our dependent variable $Y$ corresponds to the overall properties of the network (embeddedness, efficiency, resilience and geographical anchoring). The model is thus estimated separately for each of our ten outcome variables. Our main explanatory variable is the intensity of the cluster policy within the

\footnotetext{
${ }^{7}$ LeSage (2014) also states that networks represent one situation that may involve global spillovers, supporting our choice for the SDM.
} 
area, i.e. the treatment. To rule out potential bias and possible competing hypothesis, we introduce control variables at the network, territorial, and technological specialisation levels. As mentioned aboce, all the explanatory variables, as well as the treatment, are lagged one period in order to lessen endogeneity problems due to system feedbacks.

The number of nodes in the network is included (nb_nodes) as it is usual in network properties analysis. Even though our indicators are built in such a way that they avoid to be directly driven by the network size, one cannot exclude that some network properties could still be influenced by size. A larger network may for instance face more hierarchy or allow a more international anchoring thanks to the higher visibility/reputation acquired by some actors.

Moreover, based on the literature on collaboration ties formation, actors are more likely to enter networks if the benefits they expect to get from the collaboration exceed the cost of forming or maintaining ties (Jackson and Wolinski, 1996). As for the specific case of R\&D collaboration networks, one main condition to benefit from network participation is to hold sufficient absorptive capacities. This is a pre-requisite to be able to access and assimilate external knowledge made available through direct and indirect ties. This absorptive capacity is defined by both the amount of internal knowledge already accumulated and the diversity of this knowledge (Cohen and Levinthal, 1989). While this analysis stems from individual processes of knowledge, it has been widely transposed to the firm and regional level. Recent work on regional knowledge production shows for instance that innovation networks differ between regions that produce specialised and diversified knowledge (Van der Wouden and Rigby, 2019). This implies that the structure of a territory's innovation network is correlated with its level of technological specialisation.

Following the absorptive capacity theory, we therefore consider that local network properties for each of our 94 NUTS3 regions depend on the total research capacities and on the degree of knowledge diversity. Research capacities are proxied by the total amount of R\&D expenditure in the area (dird). We also include local GDP to $(g d p)$ to control more widely for the significant disparity in size and the state of the local economy. We expect positive impacts on network embeddedness, efficiency and resilience. The impact on the geographical anchoring is less obvious. A high level of local R\&D and 
economic activity may favour local interactions, but it can also favour collaboration with more distant partners as it ensures a higher ability to benefit from leading edge knowledge.

Diversity of local knowledge is accounted for by introducing the Krugman Specialisation Index (KSI). KSI measures the distance between the distributions of patent shares in a department and at the country level. More precisely, this relative measure of specialisation considers a department to be specialised if the distribution of its patenting activities across technological fields ${ }^{8}$ differs from the average distribution observed at the country level. The Krugman specialisation index takes value zero if department $i$ has a patents distribution identical to the rest of the country, indicating that department $i$ is not specialised, and takes a maximum value of 2 if it has no technological fields in common with the rest of the country, reflecting strong sectoral specialisation; the higher the KSI, the greater the regional specialisation. A negative effect of this variable is expected on network embeddedness, since, according to the absorptive capacities, a more diversified industrial structure would favour collaborations and therefore lead to more connected networks. The impact on network efficiency is less clear: on the one hand, most specialised areas could be more likely to exhibit high clustering coefficients due to the presence of technological communities. On the other hand, social proximity (clustering for instance) could be required to counterbalance the lack of information and confidence that could arise is case of diversity.

In order to identify the proper effect of the Cluster policy, we also need to control for the other public support to private $R \& D$. Direct $R \& D$ subsidies allocated to local companies are therefore introduced as regressors. There are indirect R\&D policies as well in France. The Research Tax Credit is the most important one in terms of financial amounts but we do not include it here. It is not conditioned on any form of collaboration among firms or between science and industry. It has therefore no reasons to induce any direct specific change in the innovation network. Moreover, as it is proportional to the amount of $R \& D$, it would not add a lot to our $R \& D$ expenditure variable. Regional, national and international direct supports are for their part often conditioned on collaborative behaviours. This is especially the case at

\footnotetext{
${ }^{8}$ Technological fields are based on the aggregation of the International Patent Classification (IPC) codes, proposed by the World Intellectual Property Organization (Schmoch, 2008). This classification aggregates IPC codes into 35 technological fields.
} 
the EU level where almost all tools are based on collaboration. We therefore expect significant impact of such subsidies on the network properties. The impact on the geographical features would of course depend on the level at which the subsidy policy is implemented. We therefore distinguish the local amount of regional, national and EU subsidies. We introduce three variables:

sub_region (subsidies received from local authorities, i.e., essentially regions and departments); sub_nat (total of the subsidies received from various French Ministries, i.e., national subsidies) and sub_cee (European subsidies received from the European Commission). The rationale behind distinguishing between local, national and European subsidies is due to the fact that these subsidies have different objectives depending on donors' policy choices and are therefore likely to have different effects on the structure of innovation networks. For example, European subsidies, particularly received under the Framework Programmes, are more oriented towards strengthening international cooperation than subsidies granted by local authorities or national administrations.

Furthermore, it is widely acknowledged that there is no "one size fits all" policy. To this regard, an important concern for national cluster programs evaluation is to identify whether the policy is more efficient under certain contexts. Grillitsch and Asheim (2018) argued that the ability of place-based policies to foster knowledge networks and local dynamics greatly depends on the initial local industrial structure. Cluster policies would therefore have different effects depending on the level of specialisation of regions. In order to test this hypothesis, the Krugman Specialisation Index was used to proxy the level of technological specialisation for each department during the pre-policy period (1999-2004). The recommended approach to assessing treatment effect heterogeneity is to model the statistical interaction between the treatment and individual characteristics that define subgroups of the population. Departments were therefore divided into two subgroups based on the median KSI value: departments with a KSI below the median are defined as low specialised departments (KSII) and departments with a KSI above the median as highly specialised departments (KSI2).

To investigate treatment effect heterogeneity across the two groups of departments we extended our baseline model (Equation [5]) by allowing an interaction between the treatment intensity and dummy variables indicating the level of specialisation (low/ highly specialised departments). This allowed us to 
examine the effect of cluster policies given the level of regional technological specialisation. This issue is all the more important in the French context where the national cluster policy has been recently reoriented towards a more reduced number of clusters, more diversified due to merging, often at the benefice of the largest and more diversified areas.

Finally, it is worth making a few observations regarding the model's interpretation. Unlike least-squares approaches, in the SDM model the derivative of $y_{i}$ with respect to the $k$ th explanatory variable $x_{i k}$ usually does not equal $\beta_{k}$, and the derivative of $y_{i}$ with respect to $x_{j k}$ (for $j \neq i$ ) usually does not equal 0 . This can be seen by rewriting Equation [4] in vector form:

$$
Y_{t}=\alpha \iota_{N}+\rho W Y_{t}+X_{t-1} \beta+W X_{t-1} \theta+\varepsilon_{t}
$$

Which implies that:

$$
Y_{t}=\left(I_{N}-\rho W\right)^{-1} \alpha l_{N}+\left(I_{N}-\rho W\right)^{-1}\left(X_{t-1} \beta+W X_{t-1} \theta\right)+\left(I_{N}-\rho W\right)^{-1} \varepsilon_{t}
$$

It follows that the matrix of partial derivatives of the dependent variable with respect to the $k$ th explanatory variable in the different departments (say, $x_{1 k}$ for $i=1 ; \ldots ; N$ ) at a particular point in time $t$ is:

$$
\left[\frac{\partial Y}{\partial x_{1 k}} \cdot \frac{\partial Y}{\partial x_{N k}}\right]_{t}=\left[\begin{array}{ccc}
\frac{\partial y_{1}}{\partial x_{1 k}} & \cdots & \frac{\partial y_{1}}{\partial x_{N k}} \\
\vdots & \ddots & \vdots \\
\frac{\partial y_{N}}{\partial x_{1 k}} & \cdots & \frac{\partial y_{N}}{\partial x_{N k}}
\end{array}\right]_{t}=\left(I_{N}-\rho W\right)^{-1}\left[\begin{array}{cccc}
\beta_{k} & w_{12} \theta_{k} & \cdot & w_{1 N} \theta_{k} \\
w_{21} \theta_{k} & \beta_{k} & \cdot & w_{2 N} \theta_{k} \\
\cdot & \cdot & \cdot & \cdot \\
w_{N 1} \theta_{k} & w_{N 2} \theta_{k} & \cdot & \beta_{k}
\end{array}\right]
$$

Assuming that the spatial weight matrix is constant over time, the matrix on the right-hand side of Equation [8] is independent of the time index $t$ (Elhorst, 2014a). These calculations are therefore equivalent to those presented in LeSage (2008) and LeSage and Pace (2009) for cross-sectional setting. The only major difference in the panel setting is computational in that given the dimension of the data in a panel $(N T)$, a block diagonal matrix $I_{T} \otimes W$, whose diagonal blocks are the spatial weight matrix is used instead of the spatial weight matrix itself (Piras, 2014).

The average of the diagonal elements of the matrix resulting from the right-hand side of Equation [8] is labelled by LeSage (2008) as the average direct effect/impact. This is the impact of changes in the $i$ th 
observation of variable $k$, averaged over the $N$ departments. For example, let's consider $k$ is the treatment variable i.e. the cluster policy, the average direct effect provides a summary measure of the impact of the treatment of department $i$ on its own innovation network. The average effect on department $i$ resulting from changes in the treatment of other departments is referred to as average indirect effect/impact. This is the average of either the row sums or the column sums of the non-diagonal elements of the matrix resulting from the right-hand side of Equation [8]. LeSage (2008) also defined the average total effect/impact as the average total cumulative effect, i.e., the sum of the average direct effect and the average indirect effect ${ }^{9}$. The estimations of different effects are performed under the Lee$\mathrm{Yu}$ correction (Lee and $\mathrm{Yu}, 2010 \mathrm{a} ; 2010 \mathrm{~b}$ ) using the MATLAB routines sar_panel_FE and panel_effects_sdm, made available by Elhorst (2014b), to estimate spatial Durbin models.

\section{Empirical results and discussion}

Research questions were formulated in the second section following four network topologies that are beneficial for regional innovation: embeddedness or connectivity, efficiency, resilience and geographical anchoring. This section comments on the results of the estimation of Equation [5] with and without the interaction between the treatment intensity and dummy variables indicating the level of specialisation. Furthermore, as noted in Section 3.2, the SDM model estimates cannot be interpreted as partial derivatives in the typical regression model fashion. We therefore turn to the summary measures of direct, indirect and total effects presented in Tables 2 to 5 . The full set of partial derivatives or coefficients are available upon request.

There is a positive and significant direct effect of the French cluster policy on the density of innovation networks. However, the total effect is not significant. This suggests that reinforcing cluster policies in neighbouring departments might cancel out the positive direct effects on density and therefore on the embeddedness of local innovation networks. We also found that the policy has increased the fragmentation of innovation networks in low specialised departments. This total effect is mostly

\footnotetext{
${ }^{9}$ In what follows, the word 'average' will be omitted when referring to the different types of effects for sake of clarity.
} 
comprised of the indirect effect suggesting that reinforcing cluster policies in neighbouring departments increase the fragmentation of the innovation networks of low specialised departments. This could be explained by the fact that because of the cluster policy, the local innovation networks of low specialised departments get divided into several specialised components, i.e., groups of connected actors sharing similar or related specialisation. This is in line with previous studies suggesting that cognitive proximity is an important, and perhaps even the most important determinant in R\&D collaboration (Nooteboom et al., 2007; Boschma and Frenken, 2010; Broekel, and Boschma, 2016). Overall, the results are rather mixed and there is no clear evidence supporting that the French cluster policy has reinforced the embeddedness of local innovation networks.

Regarding network efficiency, the French cluster policy had a negative total effect on the average path length in the innovation networks of all departments. This suggests an increase in network connectivity due to the cluster policy, making knowledge diffusion easier. This negative total effect on the average path length is more significant for highly specialised departments. In addition to the reduction of the average path length, highly specialised departments have also experienced a significant increase of their network's cluster coefficient due to the cluster policy (total effect). The cluster policy has therefore contributed to the reinforcement of the network efficiency in highly specialised departments. The smallworld nature of the local innovation networks of those departments has been reinforced through the decrease of the average path length and the increase of the cluster coefficient. A complementary qualitative analysis has shown that specialised departments are essentially departments in which production and agricultural activities are predominant and whose innovation networks are relatively small compared to those of low-skilled departments. It therefore appears that the structuring effects of French clusters, in terms of network efficiency, are more observable in specialised regions. This may question the recent reorientation of the French cluster programme towards big clusters, often located in the largest and more diversified areas. 


\begin{tabular}{|c|c|c|c|c|c|c|c|}
\hline & & \multicolumn{2}{|c|}{ Density } & \multicolumn{2}{|c|}{$\begin{array}{l}\text { Fragmentation } \\
\text { index }\end{array}$} & \multicolumn{2}{|c|}{$\begin{array}{l}\text { Share of the network's } \\
\text { main component }\end{array}$} \\
\hline & & Model 1 & Model 2 & Model 1 & Model 2 & Model 1 & Model 2 \\
\hline \multicolumn{8}{|l|}{ Direct effects } \\
\hline & nb_nodes & 0.000 & 0.000 & 0.000 & 0.000 & $0.000 * *$ & $0.000 * * *$ \\
\hline & $\operatorname{gdp}(\log )$ & $-0.035^{*}$ & -0.028 & $0.222 * *$ & $0.174 *$ & -0.059 & -0.040 \\
\hline & dird $(\log )$ & 0.002 & 0.002 & -0.014 & -0.010 & -0.005 & -0.002 \\
\hline & sub_region (log) & 0.000 & 0.000 & 0.000 & 0.000 & 0.000 & 0.000 \\
\hline & sub_nat (log) & $-0.003 * * *$ & $-0.003 * * *$ & $0.010 * * *$ & $0.010 * * *$ & $-0.007 * * *$ & $-0.008 * * *$ \\
\hline & sub_cee (log) & 0.000 & 0.000 & $-0.002 *$ & $-0.002 *$ & 0.001 & 0.001 \\
\hline & KSI & $0.020 * * *$ & & $-0.055^{*}$ & & $0.065 * *$ & \\
\hline & treatment_int & $0.024 *$ & & -0.057 & & 0.057 & \\
\hline & treatment_int $*$ KSI1 & & $0.026^{*}$ & & -0.049 & & 0.048 \\
\hline & treatment_int $*$ KSI2 & & 0.031 & & -0.105 & & 0.123 \\
\hline \multicolumn{8}{|l|}{ Indirect effects } \\
\hline & nb_nodes & 0.000 & 0.000 & $0.000^{*}$ & $0.000 *$ & 0.000 & $0.000^{*}$ \\
\hline & $\operatorname{gdp}(\log )$ & -0.019 & -0.039 & -0.007 & -0.098 & -0.126 & -0.240 \\
\hline & dird $(\log )$ & -0.008 & -0.007 & $-0.052 *$ & -0.043 & 0.022 & 0.022 \\
\hline & sub_region (log) & -0.001 & -0.001 & 0.001 & 0.002 & -0.003 & -0.003 \\
\hline & sub_nat (log) & 0.001 & 0.001 & 0.010 & 0.009 & $-0.013 *$ & $-0.013 *$ \\
\hline & sub_cee (log) & 0.000 & 0.000 & -0.001 & -0.001 & $0.004 *$ & $0.004 *$ \\
\hline & KSI & -0.003 & & 0.018 & & 0.084 & \\
\hline & treatment_int & -0.017 & & 0.239 & & -0.219 & \\
\hline & treatment_int $*$ KSI1 & & -0.005 & & $0.381 * *$ & & -0.070 \\
\hline & treatment_int $*$ KSI2 & & -0.044 & & 0.113 & & $-0.460 * *$ \\
\hline \multicolumn{8}{|l|}{ Total effects } \\
\hline & nb_nodes & 0.000 & 0.000 & $0.000^{*}$ & $0.000 * *$ & 0.000 & 0.000 \\
\hline & $\operatorname{gdp}(\log )$ & -0.054 & -0.067 & 0.215 & 0.076 & -0.185 & -0.281 \\
\hline & dird $(\log )$ & -0.007 & -0.005 & $-0.066^{* *}$ & $-0.053 *$ & 0.017 & 0.020 \\
\hline & sub_region (log) & -0.001 & -0.001 & 0.001 & 0.002 & -0.003 & -0.003 \\
\hline & sub_nat (log) & -0.002 & -0.002 & $0.020 * *$ & $0.019 * *$ & $-0.020 * *$ & $-0.021 * *$ \\
\hline & sub_cee (log) & 0.000 & 0.000 & -0.003 & -0.003 & $0.005^{*}$ & $0.005^{*}$ \\
\hline & KSI & 0.016 & & -0.037 & & $0.149 * *$ & \\
\hline & treatment_int & 0.007 & & 0.182 & & -0.163 & \\
\hline & treatment_int $*$ KSI1 & & 0.021 & & $0.332 *$ & & -0.022 \\
\hline & treatment_int $*$ KSI 2 & & -0.012 & & 0.007 & & $-0.337 *$ \\
\hline
\end{tabular}

Note: Statistical significance: $* \mathrm{p}<0.10, * * \mathrm{p}<0.05, * * * \mathrm{p}<0.01$

Thus, much more than the number of actors present in innovation networks, regional specialisation constitutes a key factor for the success of cluster policies. This finding therefore provides strong support for innovation network policies which support regional growth by building around existing place-based capabilities; besides cluster policies, such policies also include smart specialisation strategies (Balland et al., 2018) for example. 


\begin{tabular}{|c|c|c|c|c|c|}
\hline & & \multicolumn{2}{|c|}{ Log Clustering coefficient (ratio) } & \multicolumn{2}{|c|}{ Average path length (ratio) } \\
\hline & & Model 1 & Model 2 & Model 1 & Model 2 \\
\hline \multicolumn{6}{|l|}{ Direct effects } \\
\hline & nb_nodes & 0.000 & 0.000 & $0.000 * * *$ & $0.000 * * *$ \\
\hline & $\operatorname{gdp}(\log )$ & $6.521 *$ & $8.157 * *$ & 0.199 & 0.136 \\
\hline & dird $(\log )$ & 0.033 & -0.147 & 0.010 & 0.015 \\
\hline & sub_region (log) & 0.016 & 0.001 & 0.000 & 0.000 \\
\hline & sub_nat $(\log )$ & 0.149 & 0.153 & 0.002 & 0.003 \\
\hline & sub_cee (log) & $-0.089 * *$ & $-0.086^{* *}$ & 0.001 & 0.000 \\
\hline & KSI & -0.659 & & -0.042 & \\
\hline & treatment_int & -0.244 & & 0.157 & \\
\hline & treatment_int $*$ KSI1 & & -1.731 & & 0.162 \\
\hline & treatment_int $*$ KSI2 & & 3.237 & & 0.078 \\
\hline \multicolumn{6}{|c|}{ Indirect effects } \\
\hline & nb_nodes & 0.000 & 0.000 & 0.000 & 0.000 \\
\hline & $\operatorname{gdp}(\log )$ & 0.515 & 6.238 & -0.480 & -0.598 \\
\hline & dird $(\log )$ & -0.671 & -1.220 & $0.122 * *$ & $0.130 * *$ \\
\hline & sub_region (log) & 0.044 & -0.006 & -0.004 & -0.002 \\
\hline & sub_nat $(\log )$ & 0.328 & 0.325 & $-0.040 * *$ & $-0.040 * *$ \\
\hline & sub_cee (log) & -0.147 & -0.130 & $0.021 * * *$ & $0.020 * * *$ \\
\hline & KSI & -0.187 & & 0.087 & \\
\hline & treatment_int & 5.350 & & $-0.710 * *$ & \\
\hline & treatment_int $*$ KSI1 & & -0.159 & & -0.544 \\
\hline & treatment_int $*$ KSI 2 & & $12.140 *$ & & $-0.883 * *$ \\
\hline \multicolumn{6}{|l|}{ Total effects } \\
\hline & nb_nodes & 0.000 & 0.001 & 0.000 & 0.000 \\
\hline & $\operatorname{gdp}(\log )$ & 7.036 & $14.395^{*}$ & -0.281 & -0.462 \\
\hline & dird $(\log )$ & -0.638 & -1.367 & $0.132 * *$ & $0.145 * *$ \\
\hline & sub_region (log) & 0.060 & -0.005 & -0.004 & -0.003 \\
\hline & sub_nat $(\log )$ & 0.477 & 0.478 & $-0.038 * *$ & $-0.038 * *$ \\
\hline & sub_cee (log) & $-0.237 * *$ & $-0.215^{* *}$ & $0.021 * * *$ & $0.021 * * *$ \\
\hline & KSI & -0.846 & & 0.044 & \\
\hline & treatment_int & 5.106 & & $-0.552 *$ & \\
\hline & treatment_int $*$ KSI1 & & -1.890 & & -0.381 \\
\hline 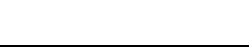 & treatment_int $*$ KSI2 & & $15.377 * *$ & & $-0.805^{*}$ \\
\hline
\end{tabular}

With respect to network resilience, we found that the French cluster policy has strengthened the assortative nature of the innovation networks for all departments, increasing the tendency of high-degree actors to interact with each other. Although the strengthening of collaborations between innovation actors is an advantage, the resilience of innovation networks also requires the strengthening of collaboration between core and peripheral actors in order to limit potential redundancy in knowledge flows and to allow the exploration of new ideas by peripheral actors and their exploitation by core actors (Cattani and Ferriani, 2008). The French cluster policy has not led to this, especially in low specialised departments for which we found a more significant positive effect on network assortativity. This result 
could be explained by the fact that most of the calls for collaborative projects managed by French clusters are competitive in nature. These "winners-take-all" competitions have probably contributed to the strengthening of collaborations "between winners". To sum up, we found no evidence that the policy has contributed to make the local innovation networks more resilient, and even worse it has contributed to the reinforcement of collaboration between core actors, leaving peripheral actors on the margins.

Table 4 Marginal effects of SDM for network resilience

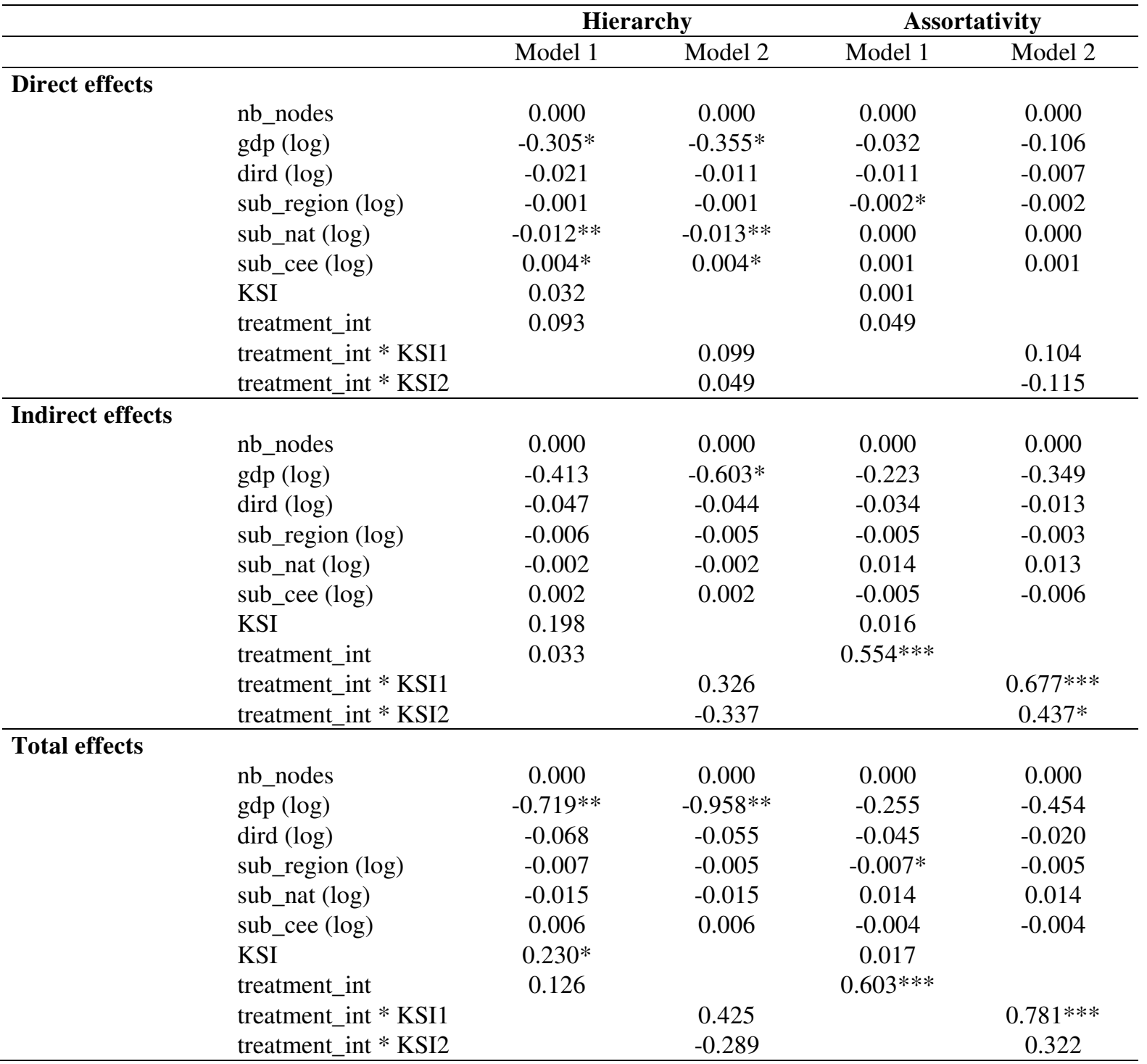

Note: Statistical significance: ${ }^{*} \mathrm{p}<0.10,{ }^{* *} \mathrm{p}<0.05,{ }^{* * *} \mathrm{p}<0.01$

Finally, these are the findings on the effects on the geographical anchoring. At the local level, we found that the French cluster policy has a negative and significant total effect on the strengthening of collaborations between local actors from low specialised departments. This result is not intuitive since 
we would expect from place-based interventions such as cluster policies to strengthen collaboration between co-located actors (Bučar and Rissola, 2018) but there are two possible explanations to this result. Firstly, low specialised departments suffering from a lack of innovative capabilities do not have a critical mass of innovative actors that would allow strategic collaborations to be formed at the local level very often. The second explanation of this result is related to the fact that some low specialised departments do not necessary suffer from a lack of innovative capabilities (for instance the western Paris region). The decrease of local collaboration in this type of departments could be the result of the involvement of local innovative actors in partnership with regional or national actors. This result is consistent with the observation made by Bernela and Levy (2017) on French clusters. While focusing on publicly-supported R\&D projects, they find no impact of the geographical proximity on the likelihood that two partners interact within a collaborative project.

At the regional level, we found for all departments a positive and significant direct effect of the policy on the strengthening of regional collaboration. However, the total effect while remaining positive is no longer significant, suggesting that the strengthening of collaboration between actors from the same region is mitigated by their involvement in partnership with actors from other regions, and vice-versa. Indeed, this result is balanced with the complementary trend observed at the national level where the negative direct effects of the policy on the strengthening of national or interregional collaboration are also no longer significant when we look at the total effects. These findings highlight the existence of competition effects between regions since the benefits of strengthening the cluster policy in one region can be moderated by the intensity of the clustering in neighbouring regions. These competition effects may also explain the non-significance of the positive total effects on the density of local innovation networks. While assessing the German 'leading-edge cluster competition' policy, Lehmann and Menter (2018) found a similar result. Their result suggests that neighbouring cluster regions could suffer from the increased attractiveness of the promoted clusters. 
Table 5 Marginal effects of SDM for network geographical anchoring

\begin{tabular}{|c|c|c|c|c|c|c|c|}
\hline & & \multicolumn{2}{|c|}{$\begin{array}{c}\begin{array}{c}\text { Share of local } \\
\text { links }\end{array} \\
\end{array}$} & \multicolumn{2}{|c|}{$\begin{array}{c}\text { Share of regional } \\
\text { links }\end{array}$} & \multicolumn{2}{|c|}{$\begin{array}{c}\text { Share of national } \\
\text { links }\end{array}$} \\
\hline & & Model 1 & Model 2 & Model 1 & Model 2 & Model 1 & Model 2 \\
\hline \multicolumn{8}{|l|}{ Direct effects } \\
\hline & nb_nodes & $0.000 * *$ & $0.000 *$ & 0.000 & 0.000 & 0.000 & 0.000 \\
\hline & $\operatorname{gdp}(\log )$ & $0.410 * * *$ & $0.348 * *$ & -0.115 & 0.091 & $-0.300 * *$ & 0.154 \\
\hline & dird (log) & -0.017 & -0.021 & 0.013 & 0.017 & 0.005 & 0.024 \\
\hline & sub_region (log) & -0.001 & -0.002 & 0.001 & 0.000 & 0.001 & 0.000 \\
\hline & sub_nat (log) & $0.010 * * *$ & 0.003 & $-0.007 * *$ & 0.002 & -0.003 & $0.009 * *$ \\
\hline & sub_cee (log) & $-0.002 * *$ & -0.001 & 0.001 & -0.001 & 0.002 & -0.002 \\
\hline & KSI & -0.045 & & -0.036 & & $0.084 * *$ & \\
\hline & treatment_int & -0.036 & & $0.112 *$ & & -0.071 & \\
\hline & treatment_int $*$ KSI1 & & -0.148 & & 0.129 & & $-0.193^{*}$ \\
\hline & treatment_int $*$ KSI2 & & -0.065 & & 0.160 & & $-0.248 *$ \\
\hline \multicolumn{8}{|l|}{ Indirect effects } \\
\hline & nb_nodes & $0.000 * * *$ & 0.000 & $0.000 * *$ & 0.000 & 0.000 & 0.000 \\
\hline & $\operatorname{gdp}(\log )$ & -0.123 & 0.261 & -0.023 & -0.110 & 0.143 & 0.133 \\
\hline & dird $(\log )$ & -0.017 & 0.034 & 0.004 & -0.021 & 0.018 & 0.040 \\
\hline & sub_region (log) & 0.003 & 0.004 & -0.001 & 0.001 & -0.002 & 0.002 \\
\hline & sub_nat (log) & 0.001 & -0.009 & 0.001 & 0.008 & -0.002 & -0.001 \\
\hline & sub_cee (log) & -0.003 & -0.004 & $0.005 * *$ & 0.001 & -0.002 & 0.002 \\
\hline & KSI & -0.044 & & 0.037 & & 0.012 & \\
\hline & treatment_int & -0.041 & & 0.016 & & -0.003 & \\
\hline & treatment_int $*$ KSI1 & & -0.387 & & -0.142 & & 0.082 \\
\hline & treatment_int $*$ KSI2 & & -0.090 & & -0.270 & & 0.282 \\
\hline \multicolumn{8}{|l|}{ Total effects } \\
\hline & nb_nodes & $0.000 *$ & 0.000 & 0.000 & 0.000 & 0.000 & 0.000 \\
\hline & $\operatorname{gdp}(\log )$ & 0.287 & $0.609 * *$ & -0.138 & -0.020 & -0.157 & 0.287 \\
\hline & dird $(\log )$ & -0.035 & 0.014 & 0.016 & -0.004 & 0.023 & 0.063 \\
\hline & sub_region (log) & 0.001 & 0.002 & 0.000 & 0.001 & -0.001 & 0.002 \\
\hline & sub_nat $(\log )$ & 0.010 & -0.006 & -0.006 & 0.011 & -0.005 & 0.008 \\
\hline & sub_cee (log) & $-0.005^{*}$ & -0.005 & $0.006 * *$ & 0.000 & 0.000 & 0.000 \\
\hline & KSI & -0.089 & & 0.002 & & 0.096 & \\
\hline & treatment_int & -0.077 & & 0.129 & & -0.074 & \\
\hline & treatment_int $*$ KSI1 & & $-0.535^{* *}$ & & -0.013 & & -0.111 \\
\hline & treatment_int $*$ KSI2 & & -0.155 & & -0.110 & & 0.034 \\
\hline
\end{tabular}

Note: Statistical significance: $* \mathrm{p}<0.10,{ }^{*} \mathrm{p}<0.05, * * * \mathrm{p}<0.01$

\section{Concluding remarks and policy implications}

Clusters have emerged as important policy instruments in the past decades, requiring evidence to support them. Yet despite the growth of a body of literature evaluating cluster policies, the changes in the structure of innovation networks resulting from cluster policies remain unclear. The research conducted here has sought to empirically assess the structural effects of cluster policies by extending the spatial Durbin model to panel data. We investigated the effects of the French cluster policy on the structure of 
local innovation networks following four network topologies that may prove to be beneficial for regional innovation, namely embeddedness or connectivity, efficiency, resilience and geographical anchoring. Network embeddedness was defined as the overall network connectivity while network efficiency refers to the "small worldness" of innovation networks. With regard to network resilience, it characterises hierarchical and disassortative innovation networks; network geographical anchoring was assessed through their tendency to include links involving local, regional and national actors. Several conclusions related to each of these topologies can be drawn from this study.

Essentially, the results highlight a positive total effect of cluster policies on the efficiency of local innovation networks, especially in the case of highly specialised departments. By increasing the smallworld nature of innovation networks from such departments, the policy has facilitated the establishment of collaborations and knowledge diffusion. In diversified regions which have achieved a critical mass in several specializations and which host major universities and research centres, the additional effect induced by cluster policies on innovation networks is weak. This finding supports the argument that regions' technological specialisation is a key factor for the success of cluster policies (Porter, 2000). Indeed, even though a high degree of specialisation could make regions more prone to exogenous shocks, policymakers should ensure that there is a minimum degree of specialisation in a region before implementing a cluster policy in that region.

Despite these positive effects, cluster policies can lead to negative effects. The results indicate an adverse effect of cluster policies on the structure of innovation networks, especially in low specialised departments. In those departments, the French cluster policy has strengthened collaboration but mostly between central actors of the networks. This suggests that the reinforcement of collaboration between core and peripheral actors is not a systematic outcome of cluster policies. It is therefore crucial for policymakers to setup the right mechanisms to support such type of collaborations in order to reinforce the resilience of innovation networks. Though the underlying mechanisms need further exploration, recent studies suggest that implementing outreach actions in order to encourage collaboration between central and peripheral actors might be more effective than imposition of policy requirements (Rossi et al. 2016). 
With respect to networks' embeddedness and their geographical anchoring (local, regional or national), our results do not allow us to identify any significant total effect of the French cluster policy. Although some direct positive effects have been observed on network density or on the regional anchoring of networks, the total effects are not significant. These results highlight the existence of a certain form of regional competition resulting from cluster policies. When a cluster is established within a region, the latter benefits from positive effects on its innovation network through the strengthening of collaborations between the innovation actors, particularly between local and regional actors in the case of the French cluster policy. However, those positive effects could be modified (increased, cancelled out or reduced) if clusters are also established within the other regions, in particular the neighbouring ones. Such competition may reinforce regional inequalities. Accordingly, as also pointed out by Lehmann and Menter (2018), the possible 'beggar-thy-neighbour' effects of cluster policies should be considered by policymakers when designing cluster policies. In practice, this would mean, for example, to evaluate exante the impacts of implementing or strengthening a cluster policy within a region on neighbouring regions.

Although this study provides interesting results, it has some limitations that should be considered. The main limit is related to the fact that patent data do not capture all collaborative processes. Therefore, our results should be corroborated by further empirical analyses using primary data from surveys on collaborations. It should also be noted that the analyses carried out in this study lead to aggregated results that do not necessarily reflect the effects of each (French) cluster individually. Although this study makes it possible to draw overall conclusions, essentially based on average effects, a more detailed and qualitative analysis of each cluster and region could reveal some differences. Still at the methodological level, we also acknowledge that our results do not establish in-depth causal effects, opening the floor for future research in this direction. But despite these limitations, this study could serve as an insightful starting point for further investigations of the structural effects of cluster policies. 


\section{Acknowledgements}

The authors thank the conference participants at the $2^{\text {nd }}$ International Workshop on Cluster Research Rethinking Clusters and the 59 $9^{\text {th }}$ ERSA Congress for useful suggestions; and Rosina Moreno and Ernest Miguelez for helpful comments on earlier versions of this article.

This work was supported by the French National Research Agency [ANR14-CE29-0005-01]; and the Auvergne-Rhône Alpes Regional Council [SCUSI-1700937101]. 


\section{Appendices}

Table 6 Descriptive statistics of the control variables

\begin{tabular}{lccccc}
\hline Control variables & $\mathrm{N}$ & Mean & St. Dev. & Min & Max \\
\hline nb_nodes & 376 & 719.96 & $1,164.559$ & 5.000 & 6,749 \\
gdp $(\log )$ & 376 & 16.351 & 0.879 & 14.234 & 19.028 \\
dird $(\log )$ & 376 & 11.194 & 1.715 & 5.599 & 15.144 \\
sub_region $(\log )$ & 376 & 2.318 & 5.311 & -6.908 & 10.085 \\
sub_nat $(\log )$ & 376 & 7.824 & 2.394 & -6.908 & 13.456 \\
sub_cee $(\log )$ & 376 & 3.924 & 4.958 & -6.908 & 10.265 \\
KSI & 376 & 0.661 & 0.237 & 0.243 & 1.835
\end{tabular}

Table 7 Correlation matrix of the control variables

\begin{tabular}{|l|l|c|c|c|c|c|c|c|}
\hline & & 1 & 2 & 3 & 4 & 5 & 6 & 7 \\
\hline 1 & nb_nodes & 1 & & & & & \\
\hline 2 & gdp (log) & 0.727 & 1 & & & & \\
\hline 3 & dird (log) & 0.665 & 0.855 & 1 & & & \\
\hline 4 & sub_region $(\log )$ & 0.276 & 0.407 & 0.441 & 1 & & \\
\hline 5 & sub_nat $(\log )$ & 0.587 & 0.739 & 0.813 & 0.471 & 1 & & \\
\hline 6 & sub_cee $(\log )$ & 0.434 & 0.647 & 0.753 & 0.364 & 0.676 & 1 \\
\hline 7 & KSI & -0.48 & -0.763 & -0.748 & -0.353 & -0.654 & -0.579 & 1 \\
\hline
\end{tabular}

Table 8 Subgroups of departments, based on KSI median value during the pre-policy period

\begin{tabular}{|l|l|}
\hline $\begin{array}{l}\text { Low } \\
\text { specialised } \\
\text { departments } \\
\text { (KS1) }\end{array}$ & $\begin{array}{l}\text { Ain; Alpes-Maritimes; Ardèche; Bouches-du-Rhône; Calvados; Charente-Maritime; Corrèze; } \\
\text { Côte-d'Or; Drôme; Eure-et-Loir; Finistère; Gard; Haute-Garonne; Gironde; Hérault; Indre-et- } \\
\text { Lorre; Loir-et-Cher; Loire-Atlantique; Loiret; Maine-et-Loire; Manche; Meurthe-et-Moselle; } \\
\text { Morbihan; Moselle; Nord; Oise; Pas-de-Calais; Bas-Rhin; Haut-Rhin; Rhône; Saône-et-Loire; } \\
\text { Haute-Savoie; Paris; Seine-Maritime; Seine-et-Marne; Yvelines; Tarn; Tarn-et-Garonne; Var; } \\
\text { Vienne; Yonne; Essonne; Hauts-de-Seine; Seine-Saint-Denis; Val-de-Marne; Val-d'Oise }\end{array}$ \\
\hline $\begin{array}{l}\text { Highly } \\
\text { specialised } \\
\text { departments } \\
\text { (KSI2) }\end{array}$ & $\begin{array}{l}\text { Aisne; Allier; Alpes-de-Haute-Provence; Hautes-Alpes; Ardennes; Ariège; Aube; Aude; Aveyron; } \\
\text { Cantal; Charente; Cher; Côtes-d'Armor; Creuse; Dordogne; Doubs; Eure; Gers; Ille-et-Vilaine; } \\
\text { Indre; Jura; Landes; Loire; Haute-Loire; Lot; Lot-et-Garonne; Lozère; Marne; Haute-Marne; } \\
\text { Mayenne; Meuse; Nièvre; Orne; Puy-de-Dôme; Pyrénées-Atlantiques; Hautes-Pyrénées; Pyrénées- } \\
\text { Orientales; Haute-Saône; Sarthe; Savoie; Deux-Sèvres; Somme; Vaucluse; Vendée; Haute-Vienne; } \\
\text { Vosges; Territoire de Belfort }\end{array}$ \\
\hline
\end{tabular}




\section{References}

Antonioli, D., Marzucchi, A., and Montresor, S. (2014). Regional Innovation Policy and Innovative Behaviour: Looking for Additional Effects, European Planning Studies, 22:1, 64-83, DOI: $10.1080 / 09654313.2012 .722977$

Arnold, E., and Boekholt, P. (2002). "Measuring 'relative effectiveness' - Can we compare innovation policy instruments?" in Boekholt, P. (ed.), Innovation policy and sustainable development: can innovation incentives make a difference? Flanders: IWT Studies, pp. 87-100

Autant-Bernard C, LeSage J (2011) Quantifying knowledge spillovers using spatial econometric models. Journal of Regional Science 51: 471-496

Balland, P.-A., Boschma, R., Crespo, J., \& Rigby, D. L. (2018). Smart specialization policy in the European Union: Relatedness, knowledge complexity and regional diversification. Regional Studies. doi:10.1080/00343404.2018.1437900

Bathelt, H., Malmberg, A., Maskell, P. (2004) Clusters and knowledge: local buzz, global pipelines and the process of knowledge creation. Progress in Human Geography, 28: 31-56.

Bellandi, M., and Caloffi, A. (2010). An Analysis of Regional Policies Promoting Networks for Innovation, European Planning Studies, 18:1, 67-82, DOI: 10.1080/09654310903343534

Bellégo, C., Dortet-Bernadet, V. (2014). L'impact de la participation aux pôles de compétitivité sur les PME et les ETI. Économie et Statistique, 471, 65-83.

Bernela, B., \& Levy, R. (2017). Collaboration networks within a French cluster: Do partners really interact with each other? Papers in Regional Science, 96(1), 115-138.

Borgatti, S. P., Everett, M. G. (1999) Models of core/periphery structures. Social Networks, 21: 375395.

Boschma, R. and Frenken, K. (2010). The spatial evolution of innovation networks: a proximity perspective. In R. Boschma, and R. Martin (Eds.), The handbook of evolutionary economic geography (pp. 120-135). Cheltenham: Edward Elgar.

Boschma, R., 2005. Does geographical proximity favour innovation?, Économie et institutions, 6-7, 111-128.

Branstetter, L. G., and Sakakibara, M. (2002). When do research consortia work well and why? Evidence from Japanese panel data. American Economic Review, 92(1), 143-159.

Braune, E., Mahieux, X., and Boncori, A.L. (2016). The Performance of Independent Active SMEs in French Competitiveness Clusters. Industry and Innovation 4(23): 313-330. http://dx.doi.org/10.1080/13662716.2016.1145574 
Breschi, Stefano and Camilla Lenzi (2016). "Co-invention networks and inventive productivity in US cities." Journal of Urban Economics 92:66-75

Broekel, T. (2012). Collaboration intensity and regional innovation efficiency in Germany-a conditional efficiency approach. Industry and Innovation 19:155-179.

Broekel, T., and Boschma, R. (2016). The cognitive and geographical structure of knowledge links and how they influence firms' innovation performance. Regional Statistics, 6(2), 3-26. https://doi.org/10.15196/RS06201

Brossard, O., Moussa, I. (2014). The French Cluster Policy Put to the Test with Differences-inDifferences Estimates. Economics Bulletin 34 (1), 520-529.

Bučar M. and Rissola G. (2018). Place-Based Innovation Ecosystems: Ljubljana Start-up Ecosystem and the Technology Park Ljubljana (Slovenia), EUR 29502 EN, Publications Office of the European Union, Luxembourg, ISBN 978-92-79-98264-4, doi:10.2760/717413, JRC114454.

Buisseret, T., Cameron, H. \& Georghiou, L. (1995). What difference does it make? Additionality in the public support of R\&D in large firms, International Journal of Technology Management, 4(5), pp. $587-600$.

Burt, Ronald S. (1992). Structural Holes. Cambridge, Mass.: Harvard University Press.

Caloffi, A., Rossi, F. and Russo, M. (2015). "What makes SMEs more likely to collaborate? Analysing the role of regional innovation policy". European Planning Studies, vol. 23(7), pp. 1245-1264.

Caloffi, A., Rossi, F., and Russo, M. (2017). A tale of persistent network additionality, with evidence from a regional policy. Working Paper CIMR - Centre for Innovation Management Research n.38

Camagni, R.P. (1995). The Concept of Innovative Milieu and its Relevance for Public Policies in European Lagging Regions. Papers in Regional Science 74, 317-340.

Capello, R. and Faggian, A. (2005). Collective learning and relational capital in local innovation processes. Regional studies, 39(1), 75-87.

Cattani, G., Ferriani, S. (2008). A Core/Periphery Perspective on Individual Creative Performance: Social Networks and Cinematic Achievements in the Hollywood Film Industry. Organization Science 19(6):824-844. https://doi.org/10.1287/orsc.1070.0350

Clarysse, B., M. Wright and Mustar, P. (2009). Behavioural additionality of R\&D subsidies: a learning perspective, Research Policy, 38(10), 1517-1533.

Cohen W. M. and Levinthal D. A. (1989). Innovation an learning: the two faces of R\&D, The Economic Journal, 99, 569-596. 
Coleman, J. S. (1988). 'Social capital in the creation of human capital,' American Journal of Sociology, 94, S95-S120.

Coleman, J. S. (1990). Foundations of social theory. Cambridge, MA: Harvard University Press.

Crespo, J., Suire, R. and Vicente, J. (2015). Network structural properties for cluster long-run dynamics: evidence from collaborative R\&D networks in the European mobile phone industry. Industrial and Corporate Change, 25(2), 261-282.

Crespo, J., Suire, R., and Vicente, J. (2014). Lock-in or lock-out? How structural properties of knowledge networks affect regional resilience. Journal of Economic Geography, 14(1), 199-219.

Cunningham, P., and Ramlogan, R. (2016). "The impact of innovation networks" in Edler, J., Cunningham, P., Gok, A.and Shapira, P. (ed.) Handbook of innovation policy impact. Edward Elgar, pp. 279-317

De Noni, I., Ganzaroli, A. and Orsi, L. (2017). The impact of intra-and inter-regional knowledge collaboration and technological variety on the knowledge productivity of European regions. Technological Forecast. Social. Change 117, 108-118.

D'Este, P., Guy, F., Iammarino, S. (2013). Shaping the formation of university-industry research collaborations: what type of proximity does really matter? J. Econ. Geogr. 13:537-558. http://dx.doi.org/10.1093/jeg/lbs010.

Doloreux, D. (2002). What we should know about regional systems of innovation, Technology in Society, 24(3), pp. 243-263. doi: 10.1016/S0160-791X(02)00007-6

Doloreux, D. and Parto, S. (2005). Regional innovation systems: Current discourse and unresolved issues, Technology in Society, 27(2), pp. 133-153. doi: 10.1016/j.techsoc.2005.01.002

Elhorst, J.P. (2010). Applied spatial econometrics: raising the bar. Spatial Economic Analysis 5.1, p. 928.Elhorst, J.P. (2014a). Spatial Panel Models. Handbook of Regional Science. 10.1007/978-3642-23430-9_86.

Elhorst, J. P. (2014b). Spatial econometrics: from cross-sectional data to spatial panels. Heidelberg, New York, Dordrecht, London: Springer.

Falck, O., S. Heblich, and Kipar. S. (2010). Industrial Innovation: Direct evidence From a ClusterOriented Policy. Regional Science and Urban Economics 40 (6), 574-582.

Fingleton B. and LeGallo J. (2012). Endogéneité et autocorrélation spatiale: quelle utilité pour le modèle de Durbin? Revue d'économie régionale et urbaine 1:3-17. 
Fleming, L. and Frenken, K. (2007) The evolution of inventor networks in the Silicon Valley and Boston regions, Advances in Complex Systems 10, 53-71.

Fleming, L., C. King and Juda, A. I. (2007). 'Small worlds and regional innovation,' Organization Science, 18(6), 938-954.

Galaso, P. (2017). Network topologies as collective social capital in cities and regions: a critical review of empirical studies, European Planning Studies, DOI: 10.1080/09654313.2017.1406898

Georghiou B., and Clarysse, B. (2006). Introduction and Synthesis, in: OECD (Ed.), Government R\&D Funding and Company Behaviour: Measuring Behavioural Additionality. OECD Publishing,

Giuliani, E., Matta, A., Pietrobelli, C. (2016). Networks, Cluster Development Programs, and Performance: The Electronics Cluster in Córdoba, Argentina, in: Stucchi, R., 2016. The Impact Evaluation of Cluster Development Programs: Methods and Practices. Inter-American Development Bank, 117-150.

Gok, A. and Edler, J. (2012). The use of behavioural additionality evaluation in innovation policy making. Research Evaluation, 21 (4), 306-318.

Graf H, Henning T. (2009). Public research in regional networks of innovators: A comparative study of four East German regions. Regional Studies 43: 1349-1368

Granovetter, M. S. (1985). 'Economic action and social structure: the problem of embeddedness,' American Journal of Sociology, 91(3), 481-510.

Grillitsch, M., and Asheim, B. (2018). Place-based innovation policy for industrial diversification in regions. European Planning Studies, 26(8), 1638-1662.

He, S., MacNeill, S., and Wang J. (2013). Assessing Overall Network Structure in Regional Innovation Policies: A Case Study of Cluster Policy in the West Midlands in the UK, European Planning Studies, DOI: 10.1080/09654313.2013.812066

Hottenrott, H., and Lopes-Bento, C. (2014). (International) R\&D collaboration and SMEs: The effectiveness of targeted public R\&D support schemes. Research Policy, 43(6), 1055-1066.

Jackson, M. O., and Wolinsky, A. (1996). A strategic model of social and economic networks. Journal of economic theory, 71(1), 44-74.

Kogut, B. and Walker, G. (2001). 'The small world of Germany and the durability of national networks,' American Sociological Review, 66(3), 317-335.

Lallement, R., and Harfi, M. (2016). "Quinze ans de politiques d'innovation en France". 10.13140/RG.2.1.3349.7362. 
Larosse, J. (2001). “The Evolution of Innovation Policy and the Emergence of a 'New Economy' in Flanders" in Belgian Federal Office for Scientific, Technical and Cultural Affairs (ed.), Belgian Report on Science, Technology and Innovation 2001 The Belgian Innovation System: Lessons and Challenges, pp.43-62

Lee L.F. and Yu J. (2010a). Estimation of spatial autoregressive panel data models with fixed effects. Journal of Econometrics 154(2):165-185

Lee L.F. and Yu, J. (2010b). A spatial dynamic panel data model with both time and individual fixed effects. Econometric Theory 26(2):564-597

Lehmann, E., and Menter, M. (2018). Public cluster policy and neighboring regions: beggar-thyneighbor?, Economics of Innovation and New Technology, 27:5-6, 420-437.

LeSage J. (2014). What regional scientists need to know about spatial econometrics. The Review of Regional Studies 44: 13-32

LeSage J. and Pace, R. (2009). Introduction to spatial econometrics. Chapman et Hall/CRC.

LeSage, J. (2008). An Introduction to Spatial Econometrics. Revue d'économie industrielle, 123:19-44

Lucena-Piquero, D., and Vicente, J. (2019). The visible hand of cluster policy makers: An analysis of Aerospace Valley (2006-2015) using a place-based network methodology. Research Policy, $48(3), 830-842$.

Manski, C. (1993). Identification of Endogenous Social Effects: The Reflection Problem. Review of Economic Studies 60.3, p. 531-542.

McPherson, M., Smith-Lovin, L., and Cook, J. M. (2001). Birds of a feather: Homophily in social networks. Annual Review of Sociology, 27, 415-444.

Nishimura, J., Okamuro, H. (2011a). R\&D Productivity and the Organization of Cluster Policy: An Empirical Evaluation of the Industrial Cluster Project in Japan. The Journal of Technology Transfer 36 (2), 117-144.

Nishimura, J., Okamuro, H. (2011b). Subsidy and Networking: The Effects of Direct and Indirect Support Programs of their Cluster Policy. Research Policy 40 (5), 714-727.

Nooteboom B. and Klein-Woolthuis R. (2005). Cluster dynamics, in BOSCHMA R. A. and KLOOSTERMAN R. C. (Eds) Learning from Clusters: A Critical Assessment from an Economic-Geographical Perspective, pp. 51-68. Springer, Dordrecht.

Nooteboom, B., Van Haverbeke, W., Duysters, G., Gilsing, V., van den Oord, A. (2007). Optimal cognitive distance and absorptive capacity. Research Policy, 36: 1016-1034. 
Pike, A., Dawley, S., Tomaney, J. (2010). Resilience, adaptation and adaptability. Cambridge Journal of Regions, Economy and Society, 3: 59-70.

Piras, G. (2014). Impact estimates for static spatial panel data models in R. Letters in Spatial and Resource Sciences, 7.3 (2014): 213-22

Porter, M. E. (2000). "Location, Competition, and Economic Development: Local Clusters in a Global Economy.” Economic Development Quarterly 14 (1): 15-34.

Raub, W. and Weesie, J. (1990). 'Reputation and Efficiency in Social Interactions: An Example of Network Effects', American Journal of Sociology 96: 626-54.

Rossi, F., Caloffi, A., Russo, M. (2016). Networked by design: Can policy requirements influence organisations' networking behaviour? Technological Forecasting and Social Change, 105, 203214.

Rothgang, M.; Cantner, U.; Dehio, J.; Engel, D.; Fertig, M.; Graf, H.; Hinzmann, S.; Linshalm, E.; Ploder, M.; Scholz, A.M.; Töpfer, S. (2017). Cluster policy: Insights from the German leading edge cluster competition. J. Open Innov. Technol. Mark. Complex, 3, 18

Sakakibara, M. (1997). Evaluating government-sponsored R\&D consortia in Japan: who benefits and how?. Research Policy, 26(4-5), 447-473.

Schilling, M. A. and Phelps, C. C. (2007), 'Interfirm collaboration networks: the impact of large-scale network structure on firm innovation,' Management Science, 53(7), 1113-1126.

Schmoch, U. (2008). Concept of a Technology Classification for Country Comparisons; Final Report to the World Intellectual Property Organisation (WIPO); Revised August 2011; WIPO: Geneva, Switzerland. Available online: www.wipo.int/export/sites/www/ipstats/en/statistics/patents/pdf/wipo_ipc_technology.pdf

Simmie, J., Martin, R. (2010). Regional economic resilience: towards an evolutionary approach. Cambridge Journal of Regions, Economy and Society, 3: 29-51.

Ter Wal, A. L. and Boschma R. (2009). Applying social network analysis in economic geography: framing some key analytic issues, Annals of Regional Science 43, 739-756.

Ter Wal, A. L. (2013). Cluster emergence and network evolution: A longitudinal analysis of the inventor network in Sophia-Antipolis. Regional Studies, 47, 651-668.

Töpfer, S., Cantner, U., and Graf, H. (2017). Structural dynamics of innovation networks in German Leading-Edge Clusters. The Journal of Technology Transfer. doi:10.1007/s10961-017-9642-4 
Uyarra, E., and Ramlogan, R. (2016). "The impact of cluster policy on innovation" in Edler, J., Cunningham, P., Gok, A.and Shapira, P. (ed.), Handbook of innovation policy impact. Edward Elgar, pp. 196-238

Uzzi, B. and Spiro, J. (2005). 'Collaboration and creativity: the small world problem,' American Journal of Sociology, 111(2), 447-504.

Van der Wouden, F. and Rigby, D. (2019). Co-inventor Networks and Knowledge Production in Specialized and Diversified Cities. Papers in Regional Science

Wanzenböck, I., Neuländtner, M., \& Scherngell, T. (2019). Impacts of EU funded R\&D networks on the generation of key enabling technologies: Empirical evidence from a regional perspective. Papers in Regional Science.

Wasserman, S. and Faust, K. (1994). Social Network Analysis: Methods and Applications, (Cambridge: Cambridge University Press).

Watts, D. J. and Strogatz, S. H. (1998). Collective dynamics of "small-world" networks, Nature, 393(6684), pp. 440-442. doi: 10.1038/30918 